\title{
Neuroligin1 Drives Synaptic and Behavioral Maturation through Intracellular Interactions
}

\author{
Jennifer L. Hoy, ${ }^{1}$ Paola A. Haeger, ${ }^{2}$ John R. L. Constable, ${ }^{1}$ Renee J. Arias, ${ }^{1}$ Raluca McCallum, ${ }^{1}$ Michael Kyweriga, ${ }^{1}$ \\ Lawrence Davis, ${ }^{4}$ Eric Schnell, ${ }^{3}$ Michael Wehr, ${ }^{1}$ Pablo E. Castillo, ${ }^{2}$ and Philip Washbourne ${ }^{1}$ \\ ${ }^{1}$ Institute of Neuroscience, University of Oregon, Eugene, Oregon 97403, ${ }^{2}$ Dominick P. Purpura Department of Neuroscience, Albert Einstein College of \\ Medicine, Bronx, New York 10461, ${ }^{3}$ Portland VA Medical Center and Oregon Health and Science University Department of Anesthesiology and \\ Perioperative Medicine, Portland, Oregon 97239, and ${ }^{4}$ Physics Department, University of Oregon, Eugene, Oregon 97403
}

In vitro studies suggest that the intracellular C terminus of Neuroligin1 (NL1) could play a central role in the maturation of excitatory synapses. However, it is unknown how this activity affects synapses in vivo, and whether it may impact the development of complex behaviors. To determine how NL1 influences the state of glutamatergic synapses in vivo, we compared the synaptic and behavioral phenotypes of mice overexpressing a full-length version of NL1 (NL1FL) with mice overexpressing a version missing part of the intracellular domain (NL1 $\Delta \mathrm{C})$. We show that overexpression of full-length NL1 yielded an increase in the proportion of synapses with mature characteristics and impaired learning and flexibility. In contrast, the overexpression of NL1 $\Delta \mathrm{C}$ increased the number of excitatory postsynaptic structures and led to enhanced flexibility in mnemonic and social behaviors. Transient overexpression of NL1FL revealed that elevated levels are not necessary to maintain synaptic and behavioral states altered earlier in development. In contrast, overexpression of NL1FL in the fully mature adult was able to impair normal learning behavior after 1 month of expression. These results provide the first evidence that NL1 significantly impacts key developmental processes that permanently shape circuit function and behavior, as well as the function of fully developed neural circuits. Overall, these manipulations of NL1 function illuminate the significance of NL1 intracellular signaling in vivo, and enhance our understanding of the factors that gate the maturation of glutamatergic synapses and complex behavior. This has significant implications for our ability to address disorders such as autism spectrum disorders.

\section{Introduction}

It is hypothesized that neurodevelopmental disorders such as autism spectrum disorders (ASD) could be a consequence of disrupting specific aspects of synapse formation or maturation (Zoghbi, 2003; Bourgeron, 2009; Penzes et al., 2011). Molecules known as synaptogenic cell adhesion molecules (CAMs) power-

\footnotetext{
Received Sept. 28, 2012; revised April 12, 2013; accepted April 23, 2013.

Author contributions: J.L.H., M.W., P.E.C., and P.W. designed research; J.L.H., P.A.H., J.R.L.C., R.J.A., R.M., M.K., E.S., and P.W. performed research; J.L.H., P.A.H., J.R.L.C., R.J.A., M.K., L.D., M.W., and P.E.C. analyzed data; J.L.H., M.W., P.E.C., and P.W. wrote the paper.

This work was supported by National Institute of Neurological Disorders and Stroke R01 NS065795 and Autism Speaks 1368 to P.W., by National Institute of Mental Health R01 MH081935 to P.E.C., the American Psychological Association DPN T32 MH18882-22 to J.L.H, National Science Foundation GK-12 program to L.D., and the Oregon Center for Optics to J.L.H. and L.D. P.A.H. is a PEW Latin American Fellow in the Biomedical Sciences and Becas Chile recipient. We thank Keith Beadle for establishing the immunolabeling technique in thinly sectioned brain tissue; Sheryl Moy (University of North Carolina) for excellent guidance in conducting the appropriate behavioral tests and initial characterization of our transgenic mice, and providing critical feedback on this manuscript; Cris Niell and Victoria Herman for providing comments on previous versions of this manuscript; Gary Westbrook (OHSU) for generously providing his lab's reagents and support; Miriam Deutsch (University of Oregon Physics Department) for providing lab support for extended data analysis techniques; Shawn Brown and Sebastien Valverde for technical assistance in preparation of synaptosomal fractions and Western blot generation; and Sebastien Valverde and Leah Deblander for additional assistance in training mice in the water maze and social tasks.

The authors declare no competing financial interests.

Correspondence should be addressed to Philip Washbourne, Institute of Neuroscience, 1254 University of Oregon, Eugene, 0R 97403. E-mail: pwash@uoneuro.uoregon.edu.

P.A. Haeger's present address: Department of Biomedical Sciences, School of Medicine, Catholic University of the North, Coquimbo, Chile.

DOI:10.1523/JNEUROSCI.4660-12.2013

Copyright $\odot 2013$ the authors $\quad 0270-6474 / 13 / 339364-21 \$ 15.00 / 0$
}

fully regulate these processes and have been repeatedly linked to the etiology of ASD (Gilman et al., 2011). However, few studies explore how targeted perturbations of CAMs affect synaptic state across development to modulate behaviors impacted in neurodevelopmental disorders. Recent genetic association studies have linked copy number variation, null and gain of function mutations in one particular family of CAMs, the Neuroligins, to ASD (Philippe et al., 1999; Shao et al., 2002; Jamain et al., 2003; Comoletti et al., 2004; Zhiling et al., 2008; Glessner et al., 2009). Alterations of Neuroligin1 (NL1) levels in mice also alter memory in adult animals (Kim et al., 2008; Dahlhaus et al., 2010; Jung et al., 2010), while NL1 deletion impacts both learning and normal social interactions (Blundell et al., 2010). As changes in social behavior are a core diagnostic criteria in human cases of ASD, and heterogeneous alterations in learning and memory behavior are comorbid with the disorder (Lord et al., 2000; Pardo and Eberhart, 2007; Amaral et al., 2008), NL1 manipulation has been validated to impact behavioral domains in mice homologous to those impacted in ASD. This suggests that detailed studies of how, when, and where the CAM NL1 impacts synaptic state and behavior will facilitate our ability to understand the etiology of ASD.

However, it is unclear which molecular mechanisms regulated by NL1 are relevant to the occurrence of behavioral changes characteristic of neurodevelopmental disorders. NL1 plays a prominent role in activity-dependent synaptic maturation in vitro (Chubykin et al., 2007; Wittenmayer et al., 2009), as well as alter- 
ing synapse number (Sara et al., 2005; Burton et al., 2012; Shipman and Nicoll, 2012). In vitro studies implicate NL1's intracellular PDZ and WW binding domains in facilitating its maturational activities (Iida et al., 2004; Meyer et al., 2004; Chih et al., 2005; Barrow et al., 2009; Tallafuss et al., 2010), while at least one other study proposes that a novel intracellular region drives synapse formation (Shipman et al., 2011). Other recent studies now provide compelling evidence that NL1's extracellular domain is sufficient for its posited role in glutamate receptor recruitment and influencing synapse number (Shipman and Nicoll, 2012; Budreck et al., 2013). A lack of understanding about when, where, and how these mechanisms yield reliable changes in behavior over development limits our ability to predict how specific perturbations in NL function lead to disease states.

Here, we address this gap through phenotypic analysis of targeted NL1 overexpression, a genetic perturbation specifically linked to human cases of ASD. Furthermore, we compared the synaptic and behavioral phenotypes of mice overexpressing the full-length version of NL1 (hemagglutinin (HA)-NL1FL) to a version missing the terminal 55 aa (HA-NL1 $\Delta \mathrm{C}$ ) to determine which molecular mechanisms exerted by NL1 overexpression impact behavior. We found changes in spine morphology and synaptic protein content that were consistent with inducing a large-scale maturation of synapses in HA-NL1FL animals. This corresponded to deficits in learning and behavioral flexibility in the same mice. In contrast, these aspects of synaptic maturation could not be induced by overexpression of HA-NL1 $\Delta \mathrm{C}$ in mice; instead, we observed an increase in synapse number and retention of a distinct set of scaffolding molecules. These changes corresponded to more flexible behavior in complex tasks. Finally, we demonstrate that transient HA-NL1FL overexpression in juveniles led to persistent changes in synaptic state and behavior in adults where overexpression had been eliminated for 1 month. Overexpression in the fully mature adult was also able to impair normal learning behavior. These results provide the first evidence that NL1 significantly impacts developmental processes that permanently shape circuit function and behavior, as well as the function of fully developed neural circuits.

\section{Materials and Methods}

All studies were conducted with approved protocols from the University of Oregon and the Albert Einstein College of Medicine Institutional Animal Care and Use Committees, in compliance with National Institutes of Health guidelines for the care and use of experimental animals.

Transgenic mouse generation. The green fluorescent protein (GFP) within the GFP-NL1FL construct (Fu et al., 2003) was replaced with an HA epitope tag sequence via PCR. HA-NL1FL was then removed from pCDNA3 vector and inserted into the pTRE-tight vector (Clontech) using serial digests of HindIII and XhoI followed by HindIII and XbaI. The TetO-HA-NL1FL was linearized and cut from the pTRE-tight vector with XhoI and injected into embryos. TetO-HA-NL1 $\Delta \mathrm{C}$ was similarly created except that the last 55 aa were deleted via PCR with the following reverse primer (NL1- $\Delta$ C: ggtctcgagctacctcctcatagcaagagtataatctggg). Constructs were confirmed with sequencing and successful transgenesis was confirmed via genomic PCR and Western blot of forebrain homogenate for the HA tag.

All single transgenic mice (TetO-HA-NL1 $\Delta \mathrm{C}^{+/-}$or TetO-HA$\mathrm{NL}_{1 F L}{ }^{+-}$) as well as double transgenic mice (CaMKII $\alpha$-tTA ${ }^{+/-}$; TetOHA-NL1 $\Delta \mathrm{C}^{+/-}$or CaMKII $\alpha$-tTA ${ }^{+/-}$; TetO-HA-NL1FL ${ }^{+/-}$) were first examined for basic health and behavior according to standard methods (Moy et al., 2004). It was important to consider that the insertion of novel transgenes could lead to deleterious mutations at the insertion site and result in biological effects unrelated to the specifics of transgene expression. Based on the following five observations, we are confident that all effects reported are specifically due to NL1 transgene expression and function. (1) No overt changes in health, reproduction, and reflexive behavior were observed in any single positive transgenic line. (2) The TetO-HA-NL1 ${ }^{+/-}$and TetO-HA-NL1 $\Delta \mathrm{C}^{+/-}$transgenes are never present in the homozygous state. Thus, any functional consequences of TetO transgene integration would have to be due to haplo-insufficiency. The possibility of haplo-insufficiency explaining our results is excluded as all control animals were the single positive littermates: TetO-HA$\mathrm{NL}_{1 F L}{ }^{+/-}$, TetO-HA-NL1 $\Delta \mathrm{C}^{+/-}$, or CaMKII-tTA ${ }^{+/-}$. Further, water maze data analysis comparing single positive TetO-HA-NL1FL ${ }^{+/-}$ transgenics $(n=5)$ to single positive CaMKII $\alpha$-tTA ${ }^{+/-}$transgenics $(n=$ $5)$ from the same litter revealed that the time spent in the target quadrant $(p=0.186)$ distance to platform $(p=0.453)$ and number of crosses $(p=$ 0.934 ) were statistically indistinguishable between single transgenic control groups. This was also true for TetO-HA-NL1 $\Delta \mathrm{C}^{+1-}$ versus CaMKII $\alpha$-tTA ${ }^{+/-}$mice $(p=0.864, p=0.358$ and $p=0.691, n=6$ in each group). This result allowed us to pool both types of single positive animals (TetO and CaMKII $\alpha$-tTA) as a single control group for the remainder of our studies. (3) The immunohistochemical effects of both transgenes are largely confined to the slm of the CA1 region of the hippocampus, the region in which the two transgenic proteins are predominantly localized (see Fig. 1C,D). (4) Key immunohistochemistry experiments using double positive transgenics continually on Dox revealed that there were no changes in Shank levels in the CaMKII-tTA ${ }^{+/-}$; TetO-HA-NL1FL ${ }^{+/-}$mice on Dox compared with single transgenics on Dox (Intensity: $94.8 \pm 10.7 \%$ vs $100 \pm 8 \%$, respectively, $p>0.05$, Area: $90.6 \pm 11.2 \%$ vs $100 \pm 15.9 \%, p>0.05, n=4$ animals in each group). Similarly, NR2B staining characteristics in the SLM of CaMKII-tTA ${ }^{+/-}$; TetO-HA-NL1 $\Delta \mathrm{C}^{+1-}$ double positive mice on Dox were the same as those with either the TetO-HA-NL1 $\Delta \mathrm{C}^{+/-}$transgene or the CaMKII$\mathrm{tTA}^{+/-}$transgene on Dox (Intensity: $90 \pm 12.1 \%$ vs $100 \pm 15.1 \%$, respectively, $p>0.05$, Area: $114.2 \pm 12.6 \%$ vs $100 \pm 7.8 \%, p>0.05, n=$ 4 animals in each group). (5) CaMKII-tTA ${ }^{+/-}$; TetO-HA-NL1FL ${ }^{+/-}$ mice, i.e., "double positive," mice that were administered doxycycline from birth, and therefore did not express the transgene as a protein but did have both transgenes in the genome at the times of initial testing, did not show any deficits in learning and memory behavior (see Fig. 8C, Late OEs, Test 1 and Test2) or spine size (Fig. 8E). These observations rule out the possibility that genetic disruptions by transgene insertion account for the phenotypes described in this study, but that such effects are related to expression of the proteins of interest.

Immunocytochemistry, microscopy, and image processing. The brains from four animals of each genotype were removed immediately after death and flash frozen with liquid nitrogen. Brains were stored at $-80^{\circ} \mathrm{C}$ for up to 3 weeks and then cryosectioned. Sections ( $10 \mu \mathrm{m}$ thick) were air dried on slides, fixed with $4 \%$ paraformaldehyde (PFA) solution in PBS $(1 \times \mathrm{PBS})$ for $30 \mathrm{~min}$ at $4^{\circ} \mathrm{C}$, and washed three times in $1 \times \mathrm{PBS}$ with gentle agitation. Antigen retrieval was performed with a $0.05 \%$ trypsin treatment for $5 \mathrm{~min}$ at room temperature. One percent Roche Block (Roche) and $10 \%$ normal goat sera in $1 \times \mathrm{PBS}$ was applied for $1 \mathrm{~h}$ at room temperature to block nonspecific staining. Sections were incubated overnight at $4^{\circ} \mathrm{C}$ in the following primaries diluted in blocking solution: $\alpha \mathrm{HA}$ (1:500, purified mouse IgG1; Covance), $\alpha$ PSD95 (1:400, mouse IgG2a 28/43; NeuroMab), Synapsin1 (1:400, rabbit polyclonal; Millipore), panSHANK (1:400, mouse IgG1 N23B/49; NeuroMab), and NR2B (1:300, mouse IgG2a N59/20; NeuroMab). Sections were washed three times for 5 min in $1 \times$ PBS at room temperature with gentle agitation before applying Alexa Fluor dye-labeled secondary antibodies (1:500, goat; Invitrogen) for $2 \mathrm{~h}$ at room temperature. Slides were washed and mounted in Fluoromount G+DAPI (SouthernBiotech).

Images were taken on an inverted Nikon TU-2000 microscope with an EZ-C1 confocal system (Nikon) using either a $10 \times$ air or $100 \times$ oilimmersion objective (1.45 NA). Slides were blinded to genotype. A scan at low magnification was used to determine the brightest section stained for each antibody. Laser intensities, gain, and offset ceilings were normalized to the brightest section, with saturation set to levels just above the brightest puncta of that slide. Subsequently, we confirmed that specifically stained puncta in each channel imaged were detectable in all samples. Intensity and average measures were made using Image Pro Plus (Media Cybernetics). Briefly, three $100 \mu \mathrm{m}^{2}$ regions within each hip- 
pocampal area per section were selected for analysis. Puncta were automatically thresholded and selected with the automatic bright objects feature. Measures of mean intensity and area were recorded for each punctum and average densities of puncta per $100 \mu \mathrm{m}^{2}$ were calculated. The process was repeated for 2-3 separate sections from 2-3 slides for each mouse analyzed to control for slide treatment and tissue penetration variability. Three to four mice of each genotype were analyzed in each condition constituting at least three independent experiments. The puncta analyzed additionally met the criteria of being segregated regions of intensity that were at least two SDs more intense than diffuse background regions and between 0.8 and $4 \mu \mathrm{m}^{2}$. Staining in CA1 stratum radiatum (SR), stratum lacunosum moleculare (SLM), and the molecular layer of CA3 were measured. Group means were compared and statistical significance was determined using the Student's $t$ test with $\alpha$ level set at 0.05 .

Synaptosomal preparations and Western blotting. The hippocampal formation, including the subiculum, was dissected and homogenized in 1.5 $\mathrm{ml}$ of buffer [( $4 \mathrm{~mm}$ HEPES, $320 \mathrm{~mm}$ sucrose, protease inhibitor tablets (Roche), pH 7.4] using a Potter-Elvehjem tissue grinder (Huttner et al., 1983). Homogenate was centrifuged for $10 \mathrm{~min}$ at $850 \times g$, the supernatant was removed and centrifuged at $12,000 \times g$ for an additional $10 \mathrm{~min}$. Pellet was resuspended in $2 \mathrm{ml}$ of buffer and centrifuged for $10 \mathrm{~min}$ at $14,000 \times g$. The final pellet was resuspended in $500 \mu \mathrm{l}$ of buffer. Protein concentration was determined using the Bio-Rad $\mathrm{D}_{\mathrm{C}}$ Protein Assay kit. Samples were diluted in sample buffer (312 mm Tris-HCl, pH 6.8, $50 \%$ glycerol, $10 \%$ SDS, 0.05 bromophenol blue, and $25 \%$ $\beta$-mercaptoethanol) to a final concentration of $0.3 \mu \mathrm{g} / \mu \mathrm{l}$. A total of $3 \mu \mathrm{g}$ was loaded onto an SDS-PAGE gel, with samples from four to five animals per genotype, transferred to nitrocellulose membranes, and probed with the following antibodies at a dilution of 1:1000: $\alpha$ PSD95 (mouse IgG2a 28/43; NeuroMab), $\alpha$ Synapsin1 (rabbit polyclonal; Millipore), $\alpha \mathrm{NR} 1$ (mouse IgG1; BD PharMingen), $\alpha$ NR2B (mouse IgG2a N59/20; NeuroMab), $\alpha$ NR2A (rabbit; Abcam), $\alpha$ Neuroligin1 (mouse IgG1 N97A/31; NeuroMab), $\alpha$ Neuroligin1 (mouse IgG1 4C12; Synaptic Systems), $\alpha$ HA (rabbit; Bethyl Laboratories), $\alpha$ Actin (mouse IgG2; Millipore), $\alpha$ Gephyrin (mouse IgG1; Synaptic Systems), $\alpha$ GluR1 (rabbit; Abcam), $\alpha$ GluR2 (mouse IgG2a; Millipore), $\alpha$ PanShank (mouse IgG1 N23B/49; NeuroMab), $\alpha$ Pick1 (mouse IgG1 L20/8; NeuroMab), $\alpha$ SAP97 (mouse IgG1 K64/15; NeuroMab), and $\alpha$ SAP102 (mouse IgG1 N19/2; NeuroMab).

For immunoprecipitation experiments cortices and hippocampi were dissected and homogenized in $50 \mathrm{~mm}$ HEPES, pH7.4, 0.1 mM EGTA, 100 $\mathrm{mM} \mathrm{NaCl}$, and protease inhibitors leupeptin, pepstatin TLCK, and PMSF. Triton X-100 was added to a final concentration of $1 \%$ and incubated for $2 \mathrm{~h}$ at $4^{\circ} \mathrm{C}$. Insoluble material was removed by centrifugation at $100,000 \times g$ for $1 \mathrm{~h}$. The homogenate was then adjusted to $2 \mathrm{mM} \mathrm{MgCl}$ and $2 \mathrm{mM} \mathrm{CaCl}_{2}$ and incubated with mouse anti-HA (HA.11; Covance) and incubated overnight at $4^{\circ} \mathrm{C}$. Protein G Sepharose beads $(100 \mu \mathrm{l})$ were added for $1 \mathrm{~h}$ at $4^{\circ} \mathrm{C}$. The beads were washed three times in homogenization buffer with $1 \%$ Triton X-100 and the bound protein submitted to SDS-PAGE and immunoblotting using rabbit anti-pan-NRX1 (ABN161; Millipore). All Western blots were quantified using Image Pro Plus and intensity was expressed as percentage of control. Statistical analysis was performed using Student's $t$ test with $\alpha$ level set at 0.05 .

Behavior. Basic reflex and health assessment follows (Moy et al., 2004). Briefly, mice were screened for weight differences, coat condition, abnormal tooth length, reproductive capability, gross visual functions such as forepaw reaching toward a distant object, and basic motor capabilities such as climbing rates and clinging times to an inverted wire cage lid.

Morris water maze. The Morris water maze task was based on the standard methods for spatial learning in rodents (Vorhees and Williams, 2006). Each transgenic cohort consisted of 10 double positive male mice and 10 control males positive for either the CaMKII-tTA ${ }^{+/-}$transgene or one of the TetO-driven transgenes. In the juvenile analysis, eight juvenile males and eight adult males from the same parents were compared. Briefly, the mice were tested for their ability to find an escape platform (diameter $=12 \mathrm{~cm}$ ) on four different components of the task in the following order: (1) a $2 \mathrm{~d}$ visible platform acquisition, (2) a $7 \mathrm{~d}$ hidden (submerged) platform acquisition phase with the target moved to a dif- ferent location, (3) a subsequent probe trial in the absence of the platform, and (4) hidden platform training in a new location (reversal training). In the visible platform test, each animal was given four trials per day across $2 \mathrm{~d}$ to swim to an escape platform cued by a textured cylinder extending above the surface of the water. For each trial, the mouse was placed in the pool at one of four possible locations (randomly ordered) and then given $60 \mathrm{~s}$ to find the cued platform. Once on the platform, even if placed there, they remained for at least $10 \mathrm{~s}$. Measures were taken of latency to find the platform, swimming distance, and swimming velocity via Image Pro Plus's automated tracking system and custom MATLAB programs. Following visual training, mice were trained on the hidden platform test. At day 8, mice were given a 1 min probe trial in the pool with the platform removed. On day 9 mice were tested for reversal learning using the same procedure but with the target moved to the opposite quadrant. All data were analyzed with repeated-measures ANOVA (RMANOVA), followed by Tukey-Kramer HSD post hoc test to compare means of interest, $\alpha$ level set at 0.05 .

Object recognition. The experiment was performed as described by (Bevins and Besheer, 2006). Briefly, mice were individually habituated to an open-field round container $(30 \mathrm{~cm}$ in diameter $\times 30 \mathrm{~cm}$ in height $)$ for $15 \mathrm{~min}$. The training session followed the habituation session by $10 \mathrm{~min}$. During the training session, two novel objects were placed in the open field, and the animal was allowed to explore for $20 \mathrm{~min}$. All trials were recorded by video, and measures of time spent exploring each object, time to first make contact with an object, percent of thigmotaxis, and which object was first approached were scored. Criteria for active exploration included sniffing, touching, and whisking the objects. After a delay from initial exploration of $1 \mathrm{~h}$, the animal was placed back into the same box in which one of the familiar objects during training was replaced by a novel object and allowed to explore freely for $15 \mathrm{~min}$. A preference index, a ratio of the time spent exploring the novel object (retention session) over the total time spent exploring both objects, was used to measure recognition memory. Data were calculated as mean \pm SEM. Significant differences from chance performance were determined by Wilcoxon signed rank test, with $\alpha$ level of 0.05 . Chance performance was assumed to be $50 \%$ time at each object.

Three-chambered social preference test. This test was performed as described by Moy et al. (2004). The test was performed in three phases: habituation, sociability, and preference for social novelty. During habituation the test mouse was first placed in the middle chamber and allowed to explore for $10 \mathrm{~min}$, with the doorways into the two side chambers open. Each of the two sides contained an empty wire cage. The wire cages were $11 \mathrm{~cm}$ in height, with a bottom diameter of $10.5 \mathrm{~cm}$. A weight was placed on the top of each cage to prevent movement. Wire cages were cleaned with EtOH between trials and washed thoroughly at the end of each testing day. To measure sociability, after the habituation period, the test mouse was enclosed in the center compartment of the social test box, and an unfamiliar mouse (a group housed "stranger" mouse), was placed in one of the wire cages of the side chambers chosen semirandomly. This ensured a mixture of right and left locations were tested within each group and accounted for potential biases in side preference. After the stranger mouse was in place, the test mouse was allowed to explore the entire social test box for a $10 \mathrm{~min}$ session. Sessions were recorded by video and scored by two blinded and trained observers. Number of approaches of stranger and object were scored. Total time and track distribution within each chamber was calculated using Image Pro Plus, and percentage of time spent near either cup was the metric displayed in Figure 6. To measure preference for social novelty, immediately following the sociability test, each mouse was tested in a third 10 min session with a choice of the familiar stranger versus a novel group housed stranger mouse of the same strain, age, and sex. The same measures as mentioned above were calculated and social novelty preference could be calculated by comparing time differences in the interactions with the familiar and novel mouse. Significance was determined by repeated-measures ANOVA and the $\alpha$ level set at 0.05 .

Social dominance tube test. The dominance tube apparatus (Messeri et al., 1975) was constructed out of Plexiglas and consisted of a $36 \mathrm{~cm}$ long tube with a diameter of $3.5 \mathrm{~cm}$ attached on either end to a start cylinder (measuring $10 \mathrm{~cm}$ in diameter). At the center of the tube was a removable 
perforated partition that allowed for olfactory investigation, but not physical contact. A singly housed experimental mouse and an unfamiliar group-housed mouse of similar age, weight, and sex were placed in opposite start boxes and allowed to habituate to the apparatus for $10 \mathrm{~min}$. When the animals met in the middle of the tube after the habituation period the center partition was lifted. The test was video recorded and concluded once one mouse had forced the other back. In the event of a tie, where the mice managed to squeeze past each other, the trial was noted but not included in the comparison statistics. Each mouse was subjected to three to four bouts with the same partner. Dominance behavior was measured over three separate trials for each mouse as compared with three different age and sex matched strangers. Start sides were randomized. Significance was determined by repeated-measures ANOVA with $\alpha$ level set at 0.05 and Tukey's post hoc test to report significant differences in mean performances.

Resident intruder test. Mice were housed individually for 7-8 $\mathrm{d}$ before an unfamiliar group-housed control mouse of the same sex and comparable weight was introduced to the resident's home cage. Food was removed $1 \mathrm{~h}$ before testing and all mice were habituated to the testing room for $1 \mathrm{~h}$ before introduction of the intruder mouse. Behavior was monitored and video recorded for the first $10 \mathrm{~min}$ after introduction of the intruder, or until an attack occurred, whichever came first. Measures of attack frequency, attack latency, dominant mounting, investigatory sniffing (sniffing directed toward the partner), chasing, and grooming were recorded as described previously (Duncan et al., 2004). All measures were scored by two blinded observers and the total scores between the two observers were averaged. Animals were subject to three rounds of intruder presentation. Significance was determined by repeatedmeasures ANOVA and the $\alpha$ level set at 0.05 .

Spine density and morphology quantification. Brains from three animals of each genotype were sectioned immediately after being killed by isoflurane followed by decapitation. Coronal sections ( $150 \mu \mathrm{m}$ thick) were cut at room temperature on a vibratome and placed into 2\% PFA for $30 \mathrm{~min}$. Sections were then placed on slides and covered in $1 \times$ PBS. DiI crystals (Sigma-Aldrich) were sparsely inserted into stratum oriens (SO) of region CA1 in the dorsal hippocampus. Tissue was monitored for distribution of DiI labeling between 1 and $2 \mathrm{~d}$. Four to five serial sections containing both hemispheres from each animal were labeled with DiI. Twelve well-isolated dendrites from both proximal SR, and SLM were imaged at $100 \times$ magnification using a Nikon C1 confocal microscope (see above) and quantified. Dendrites were selected for analysis on the basis of the following: (1) location within the hippocampal stratum, (2) isolation from neighboring neurites, (3) clarity of spine labeling, (4) close proximity to tissue surface to minimize light scattering, (5) low frequency of regularly spaced varicosities $\sim 2 \mu \mathrm{m}$ in diameter, and (6) validation that the neurite came from a CA1 pyramidal neuron. Regions of interest within each layer were chosen based on their distance between flanking anatomical regions, which are easily identifiable in labeled tissue. Regions $>10 \mu \mathrm{m}$ from their flanking anatomical borders were chosen to facilitate analyzing structures near the middle of each layer. Results were averaged across three animals for each genotype, yielding a total of 36 individual dendrites analyzed per hippocampal layer, per genotype. Composite images were created from 10 - to 20 - $\mu$ m-thick $z$-stacks taken at $0.2 \mu \mathrm{m}$ increments with a small pinhole. Spine density, number of spines per $10 \mu \mathrm{m}$ dendrite, and spine head area were measured using ImageJ. Before outlining spines for analysis, images were converted to 8-bit grayscale, deconvolved, and thresholded until individual spines were clearly dissociable. Spine head area in control animals within CA1 SLM ranged from $\sim 00.1$ to $0.78 \mu \mathrm{m}^{2}$, closely resembling measures reported in other studies of spine head size in SLM.

Slice electrophysiology. Animals were deeply anesthetized with isoflurane, decapitated, and the brain was rapidly removed. Transverse hippocampal slices (400 $\mu \mathrm{m}$ thick) were prepared from 4- to 9-month-old C57BL mice on a VT 1200 S slicer (Leica Microsystems) in ice-cold cutting solution containing the following (in $\mathrm{mM}$ ): 215 sucrose, $2.5 \mathrm{KCl}, 20$ glucose, $26 \mathrm{NaHCO}_{3}, 1.6 \mathrm{NaH}_{2} \mathrm{PO}_{4}, 1 \mathrm{CaCl}_{2}$, and $4 \mathrm{MgCl}_{2}$. This solution was slowly exchanged to the artificial CSF (ACSF) containing $124 \mathrm{NaCl}$, $2.5 \mathrm{KCl}, 10$ glucose, $26 \mathrm{NaHCO}_{3}, 1.6 \mathrm{NaH}_{2} \mathrm{PO}_{4}, 2.5 \mathrm{CaCl}_{2}$, and 1.3 $\mathrm{MgCl}_{2}$. Both cutting and ACSF solutions were saturated with $95 \% \mathrm{O}_{2}$ and
$5 \% \mathrm{CO}_{2}, \mathrm{pH}$ 7.4. The slices were incubated at room temperature for at least $1.5 \mathrm{~h}$ before recording.

Slices were transferred to a recording chamber and perfused with $\operatorname{ACSF}(2 \mathrm{ml} / \mathrm{min})$. All recordings were done at $30^{\circ} \mathrm{C}$ and the CA3 region was separated from the slices by a single diagonal cut. CA1 pyramidal cells were voltage clamped at -60 or $+30 \mathrm{mV}$ using patch-type pipette electrodes ( $\sim 3-4 \mathrm{M} \Omega$ ) containing the following: (in $\mathrm{mM}$ ): 123 cesium gluconate, $8 \mathrm{NaCl}, 1 \mathrm{CaCl}_{2}, 10$ EGTA, 10 HEPES, and 10 glucose, $\mathrm{pH} 7.3$ (290-295 mOsm), and connected to a Multiclamp 700A amplifier (Molecular Devices). The series resistance (Rs), typically $8-15 \mathrm{M} \Omega$, was monitored throughout the recording using $-5 \mathrm{mV}, 80 \mathrm{~ms}$ voltage steps, and those experiments in which there was a $>10 \%$ change in Rs were excluded for analysis. Pipettes were pulled on a PP-830 vertical puller (Narishige). EPSCs were evoked by monopolar stimulation with a broken patch pipette $(\sim 10 \mu \mathrm{m}$ tip $)$ and filled with ACSF. The stimulation pipettes were placed in SR $(\sim 100 \mu \mathrm{m}$ from CAl pyramidal cell body $)$ and in SLM ( $\sim 350 \mu \mathrm{m}$ from CA1 pyramidal cell body). NMDAR/AMPAR ratios were determined as follows: for AMPAR-EPSCs, cells were voltage clamped at $-60 \mathrm{mV}$, and recordings were performed in the presence of the $\mathrm{GABA}_{\mathrm{A}}$ receptor antagonist picrotoxin $(100 \mu \mathrm{M})$. Due to the inward rectification of the PP-CA1 NMDAR-EPSC (Otmakhova et al., 2002), NMDAR-EPSCs were also measured at $-60 \mathrm{mV}$ and isolated by adding the AMPAR and kainate receptor antagonist NBQX $(10 \mu \mathrm{M})$. The baseline stimulation frequency for all experiments was $0.05 \mathrm{~Hz}$. Averaged traces include at least 15 successive synaptic responses. Paired-pulse facilitation was analyzed dividing the second pulse by the first pulse amplitude with a 40 or $50 \mathrm{~ms}$ interstimulus interval in SR or SLM, respectively. NMDAR-EPSC decay kinetics was analyzed by clamping to $+30 \mathrm{mV}$ and fitting a single exponential using Origin 8.6 (OriginLab). EPSCs were elicited at $20 \mathrm{~s}$ intervals, filtered at $2.2 \mathrm{kHz}$, and acquired at $5 \mathrm{kHz}$ using custom software written in Igor Pro 4.09A (Wavemetrics). Field potentials were recorded extracellularly with patch-type pipettes filled with $1 \mathrm{M}$ $\mathrm{NaCl}$ and placed in the SLM. The functional contribution of NR2Bcontaining NMDARs was assessed by monitoring NMDAR-fEPSPs in the presence of NBQX $(10 \mu \mathrm{M})$ and picrotoxin $(100 \mu \mathrm{M})$.

Long-term potentiation at the PP-CA1 synapse (PP LTP) was measured in acute slices perfused with picrotoxin $(100 \mu \mathrm{M})$ and CGP-55845 $(3 \mu \mathrm{M})$ to block $\mathrm{GABA}_{\mathrm{A}}$ and $\mathrm{GABA}_{\mathrm{B}}$ receptors, respectively. Two independent pathways were alternately stimulated at $15 \mathrm{~s}$ intervals; one pathway received the LTP induction protocol whereas the other (naive) pathway served as control. PP LTP was induced with a theta- burst stimulation (TBS) protocol consisting of four theta-burst trains of stimuli once every $10 \mathrm{~s}$. Each theta-burst train consisted of 10 bursts every 200 $\mathrm{ms}$, each burst containing 5 stimuli at $100 \mathrm{~Hz}$. Student's $t$ test was used to determine statistical significance, with ${ }^{\star} p<0.05,{ }^{* *} p<0.01$, and ${ }^{\star * *} p<$ 0.01 . All statistics and analyses were performed with OriginPro 8.6. All data are presented as mean \pm SEM.

Auditory cortex electrophysiology. Briefly, each mouse was anesthetized with a ketamine (100 mg/kg body mass), medetomidine, and acepromazine mixture, and given supplemental doses to maintain anesthesia. Atropine and dexamethasone were also administered to reduce tracheal secretions and cerebral edema. The mouse's temperature was maintained at $37 \pm 1^{\circ} \mathrm{C}$. The left temporal cortex was surgically exposed (craniotomy and durotomy) and covered with $1.5 \%$ agarose in $0.9 \%$ saline. Tungsten electrodes, with $1-2 \mathrm{M} \Omega$ impedances were used to find cortical regions with strong multiunit responses to click trains, determined audiovisually. White noise clicks were presented at $30-80 \mathrm{~dB}$ sound pressure level (SPL), for $25 \mathrm{~ms}$ in duration with interstimulus intervals of $500 \mathrm{~ms}$ or $1000 \mathrm{~ms}$. Each mouse had one to four recording sites in layer 3-5 of auditory cortex (mean depth: $419 \mu \mathrm{m}$; range: $314-580 \mu \mathrm{m} ; n=21$ ). The rate level function measures neural spike counts driven by increasing sound amplitude in $\mathrm{AB}$ SPL for white noise clicks. The number of spikes was summed from a $50 \mathrm{~ms}$ window, beginning at the stimulus onset using a spike detection threshold of 3 SD over 40 trials. Subjects: five control male mice with 11 recording sites (range of 1-4) and five double positive male mice with 10 recording sites (range of 1-3) were used for these experiments. Significance was determined with repeatedmeasures ANOVA with the $\alpha$ level set at 0.05 .

Doxycycline regulation of NL1 overexpression. The HA-NL1FL construct contained the Tet-off responsive genetic element and was there- 
fore silenced in the presence of the tetracycline analog, Doxycycline (Dox). The Early Overexpresser (Early OE) cohort was left on a normal diet until 2 months of age, thus expressing their transgene until they were adults. They were fed a diet containing $2 \mathrm{~g} / \mathrm{kg}$ Dox for $5 \mathrm{~d}$ to induce a rapid silencing of transgene expression. That diet was replaced with a 50 $\mathrm{mg} / \mathrm{kg}$ concentration to maintain transgene suppression for the remainder of the animal's lives. Western blots on a random subset of animals from this cohort confirmed the absence of transgene expression after $7 \mathrm{~d}$ of Dox administration ( $5 \mathrm{~d}$ on $2 \mathrm{~g} / \mathrm{kg}$ Dox diet, $2 \mathrm{~d}$ on the $40 \mathrm{mg} / \mathrm{kg}$ diet). The mothers of postnatal 10 (P10) pups of the Late Overexpresser (Late $\mathrm{OE}$ ) cohort were given a diet of $2 \mathrm{~g} / \mathrm{kg}$ Dox for $5 \mathrm{~d}$ and then transitioned onto the $50 \mathrm{mg} / \mathrm{kg}$ Dox until weaning. The Late OE pups were weaned onto $40 \mathrm{mg} / \mathrm{kg}$ Dox until 2 months of age, thus not expressing the transgene until 2 months of age. The cohort remained on a regular diet for the remainder of their lives, $\sim 1$ month. Half of each brain from each subject was used in Western blot analysis to assay for transgene expression. The other half of the brain from each animal was used for DiI spine morphology analysis.

\section{Results}

\section{Generation of HA-NL1FL and HA-NL1 $\Delta C$ transgenic mice}

The intracellular C terminus of NL1 contains both PDZ binding and WW binding motifs, which are thought to underlie important aspects of glutamatergic postsynaptic development and brain function. To understand the contribution of these signaling domains to NL1's influence over behavioral and synaptic maturation within known mnemonic neural systems in vivo, we used a temporally regulated genetic system to target our manipulations to the forebrain. We generated mice that express the coding region for either NL1 full-length (NL1FL) or NL1 missing the terminal 55 aa $(\mathrm{NL} 1 \Delta \mathrm{C})$ under the promoter that is induced by the tetracycline transactivator protein (tTA). Both versions of NL1 were tagged with the HA peptide sequence on the $\mathrm{N}$ terminus to facilitate localization and quantification of transgene expression in situ (HA-NL1FL and HA-NL1 $\Delta$ C; Fig. $1 A$ ). After generation of founder groups, mice were backcrossed to the C57BL/6J strain of mice before being crossed to mice that expressed the tetracycline transactivator driven by the CaMKII $\alpha$ promoter, CaMKII$\mathrm{tTA}^{+/-}$mice. This system drives tetracycline-regulated expression in forebrain excitatory neurons (Mayford et al., 1996). Double transgenic progeny from these crosses, either CaMKIItTA $^{+/-}$;TetO-HA-NL1FL ${ }^{+/-}$(HA-NL1FL mice) or CaMKII$\mathrm{tTA}^{+/}$; TetO-HA-NL1 $\Delta \mathrm{C}^{+/}(\mathrm{HA}-\mathrm{NL} 1 \Delta \mathrm{C}$ mice $)$ were obtained at the expected Mendelian frequencies in both cases and Western blot analysis revealed that doxycycline administration, $2 \mathrm{~g} / \mathrm{kg}$ followed by $40 \mathrm{mg} / \mathrm{kg}$ in mother's food, from birth was effective in suppressing transgene protein expression (Fig. 8 $A^{\prime}$; data not shown). At 2 months of age, continuously expressing double positives from both lines were examined for their coat condition, exploratory behavior in an open field, anxiety in the elevated plus maze, ability to climb a pole, and ability to maintain grip when clinging to a cage lid. We also screened for the presence of normal acoustic startle reflexes, average weight, and incidence of mortality before testing in more complicated behavioral assays (Moy et al., 2004, 2006). In these and all subsequent assays except where stated, control groups were composed of an equal mixture of single positives possessing the CaMKII-tTA ${ }^{+/-}$, TetO-HA$\mathrm{NL}_{1 F L}{ }^{+/-}$or TetO-HA-NL1 $\Delta \mathrm{C}^{+/-}$transgenes only. In addition, normal fertility rates and the ability to successfully breed suggested preserved olfactory-mediated behaviors, consistent with the findings in subsequent behavioral assays. As no significant differences in all of these measures were found (data not shown), we proceeded to more detailed biochemical, electrophysiological, and behavioral testing.
To effectively compare and contrast the synaptic and behavioral profiles between the two lines of mice, we assayed expression levels of total HA in the hippocampus between the two lines, as well as how much NL1 was overexpressed relative to endogenous control levels via quantitative Western blot. We found no significant difference in amount of HA protein present per $5 \mu \mathrm{g}$ of forebrain homogenate $(100 \pm 5.23 \%$ HA in HA-NL1FL mice vs $102.96 \pm 1.55 \% \mathrm{HA}$ in HA-NL1 $\Delta \mathrm{C}$ mice, normalized to HANL1FL levels, $p>0.05$; Fig. $1 A$, right, top). Moreover, blots using an antibody that recognized endogenous NL1 as well as the overexpressed forms revealed each transgenic line overexpressed their respective transgenes similarly relative to single positive littermate controls ( $207.73 \pm 3.45 \%$ overexpression HA-NL1FL mice vs $219.33 \pm 2.9 \%$ overexpression in HA-NL1 $\Delta \mathrm{C}$ mice; Fig. $1 A$, right, middle). Furthermore, immunoprecipitation of the tagged constructs revealed that the samples from each line similarly coimmunoprecipitated the trans-synaptic binding partner Neurexin in vivo (Fig. $1 A$, bottom, right). This argues that both transgenes, the FL and the truncated form, were correctly targeted to the synaptic density and engaged in key trans-synaptic interactions. Immunohistochemistry on cryosectioned tissue found comparable expression levels of the transgenes in the same cell types within both transgenic lines (Fig. $1 B-D$ ). HA immunolabeling was detected in a subset of the expected forebrain nuclei and neural circuits, based on the CaMKII $\alpha$-tTA driver line. This included the amygdala (Amg) and specific cell populations within the neocortex such as the retrosplenial granular (RSG) formation and layers IV and VI of the primary sensory cortices (Fig. 1B). Neither transgene was detected in the striatum (data not shown). Importantly, HA expression in both lines of mice was observed within the hippocampal circuit, the system primarily associated with the explicit forms of learning and memory behaviors previously shown to rely on NL1 function (Blundell et al., 2010; Dahlhaus et al., 2010) (Fig. 1B, red box). Expression was observed throughout CA1, absent from region CA3, and was weak and sparsely found in dentate gyrus (Fig. $1 C, D$ ). Accordingly, HA immunoreactivity was localized within the hippocampal circuit to the SO, SR, and SLM of CA1. This suggests targeting of the overexpressed proteins to relevant dendritic structures, as expected for NL proteins.

Surprisingly, we noticed an $\sim 2$-fold increase in levels of HANL1FL and HA-NL1 $\Delta$ C in the SLM relative to the SR (SLM:SR intensity ratio $2.1 \pm 0.3$ vs $2.5 \pm 0.4, \mathrm{HA}-\mathrm{NL} 1 \mathrm{FL}$ and HA-NL1 $\Delta \mathrm{C}$ respectively, $p>0.05$; Fig. $1 B$, lower right, $C, D)$. This relative increase in HA levels in the SLM versus the SR does not parallel the relative intensity levels of PSD-95 between SLM and SR (SLM:SR ratio of PS-D95: $0.75 \pm 0.04$ vs $0.80 \pm 0.04$ respectively, $p>0.05$; Fig. $1 C, D$ ), thus synapse density cannot account for the difference in HA levels between these two strata. It is unlikely that any difference in HA localization is due to differences in trafficking between NL1FL and NL1 $\Delta C$, as both lines showed the same subcellular localization patterns. Also, we observed that both transgenes, when imaged at higher magnification in the SLM and SR, primarily localized to sites positive for PSD-95 immunolabeling and were far less frequently observed to colocalize with GABA-AR $\alpha 1$ (Fig. $1 E, F$ ). This is consistent with previous reports that NL1 trafficking to synapses is independent of C terminus signaling (Dresbach et al., 2004; Prange et al., 2004).

Finally, labeling of the HA-tag together with cell nuclei (DAPI) in hippocampal sections showed that $88 \pm 3.12 \%$ of cells in CA1 of the HA-NL1 mice express the transgene, while $93 \pm$ $1.42 \%$ of cells in CA1 of the HA-NL1 $\Delta \mathrm{C}$ mice express that transgene. Overall cell densities in the CA1 regions of both lines were 

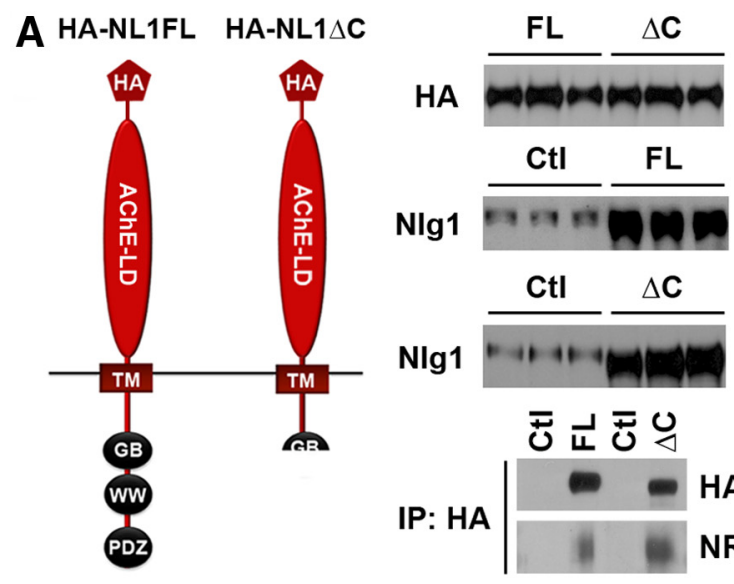

B

C

HA-NL1FL
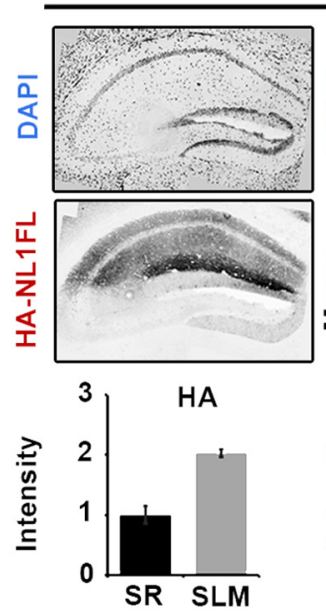

E
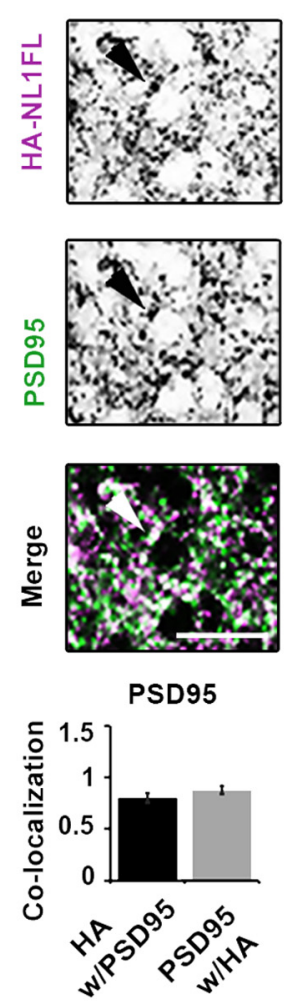

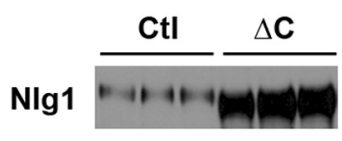

$\overline{\mathrm{U}} \mathrm{E} \overline{\mathrm{U}} \mathrm{U}$
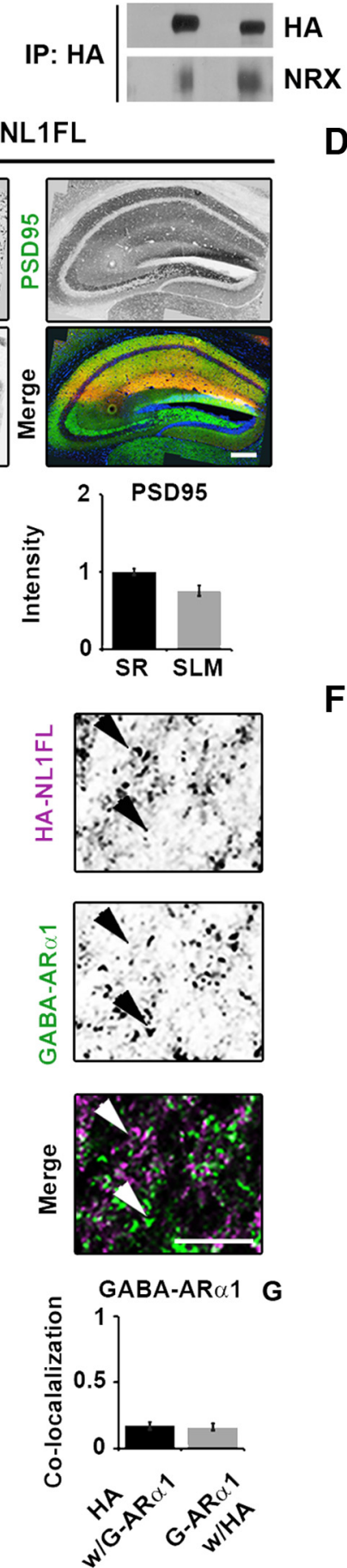

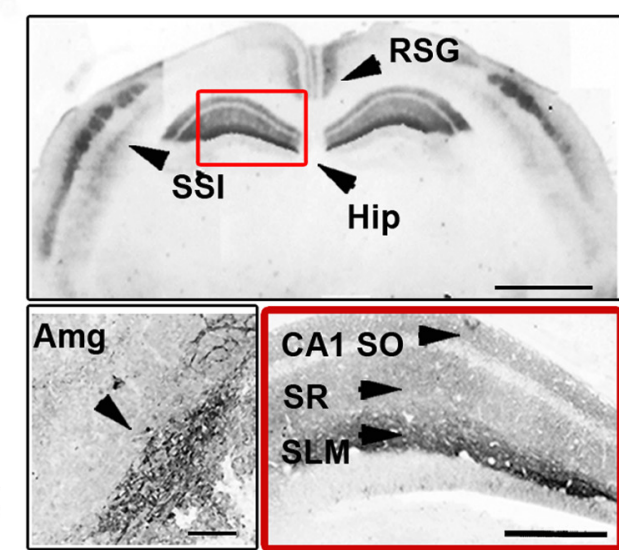

D
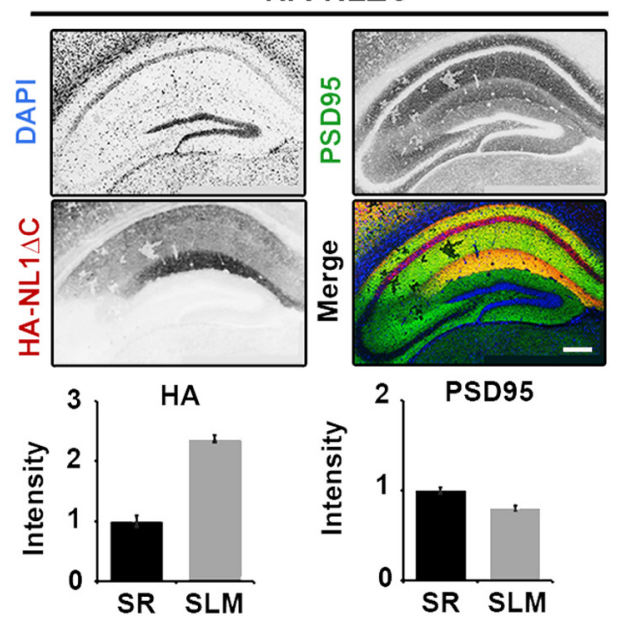

$\mathbf{F}$
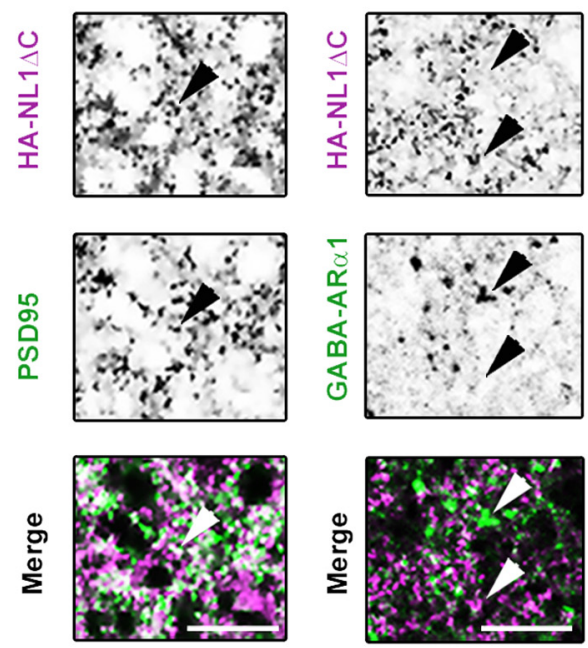

PSD95

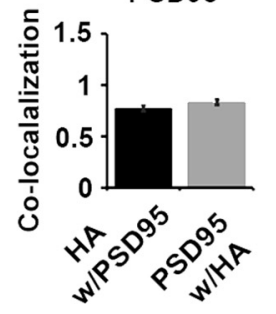

GABA-AR $\alpha 1$

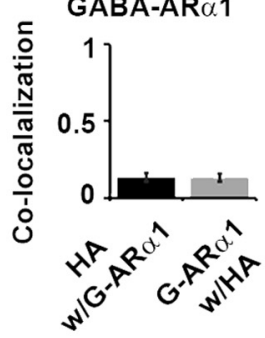


not different from each other, suggesting that nonspecific effects such as cell death would not interfere with subsequent analyses. Therefore, the expression patterns present in the two lines of mice are comparable and allowed for a straightforward comparison of synaptic and behavioral profiles.

\section{Overexpression of NL1FL and NL1 $\Delta C$ differentially modulate spines and synapses in the SLM}

Previous in vivo studies of NL1 function suggest that this gene positively regulates the size and function of excitatory synapses (Dahlhaus et al., 2010). Therefore, we hypothesized that our manipulations would significantly impact morphological features of synaptic maturity. To determine whether we could identify the predicted shifts in the synaptic population, we measured both spine morphology and the presence of mature synaptic proteins in the hippocampus of both HA-NL1FL and HA-NL $\Delta$ C mice. Given the expression pattern of our transgenes, we were afforded the opportunity to examine how such alterations may have been specific to targeted layers within the hippocampus (Fig. 1C,D). We labeled CA1 neurons in the hippocampus with DiI and imaged dendrites and spines from the SLM and SR target layers at high magnification. In HA-NL1FL mice, there was a $>2$-fold increase in the average area of spine heads in the SLM $(220.4 \pm 25.0 \%$ vs $100 \pm 8.3 \%$, respectively, $p<0.01, n=36$, Student's $t$ test), but no significant change in density (Fig. 2A). Interestingly, we did not see significant changes in spine head area $(119.8 \pm 8.2 \%$ vs $100 \pm 9.9 \%, p>0.05)$, nor density $(110.0 \pm 8.2 \%$ vs $100 \pm 4.1 \%, p>0.05)$ in the SR of HA-NL1FL animals. This is consistent with the idea that the region with the highest level of transgene expression was the most affected. In HANL1 $\Delta C$ animals, we found a significant $21 \%$ increase in the density of spines in SLM $(121.0 \pm 6.2 \%$ vs $100 \pm 10.0 \%$ normalized density, $p<0.05)$, and no significant change in spine head area (85.9 \pm $14.1 \%$ vs $100 \pm 8.5 \%$ normalized area, $p=0.08, n=36$, Student's $t$ test; Fig. $2 B)$. No significant difference in density $(114.1 \pm 4.9 \%$ vs100 $\pm 8.7 \%, p>0.05)$, nor spine head area $(115.1 \pm 10.9 \%$ vs $100 \pm 16.8 \%, p>0.05)$ was found in the SR. Therefore, overexpression of HA-NL1 $\Delta \mathrm{C}$ distinctly alters synaptic number as compared with the overexpression of HA-NL1FL. Such differences between the two transgenic lines suggest that the intracellular region deleted in NL1 $\triangle \mathrm{C}$ is required to drive an increase in the proportion of morphologically mature synaptic phenotypes when NL1FL is overexpressed.

As another measure of the maturity of synapses, we quantified the area and density of Synapsin I puncta, a marker of mature

\footnotetext{
$\leftarrow$

(Figure legend continued.) (middle). Five micrograms of total protein loaded into each lane. Immunoprecipitation (IP) using antibodies to $\mathrm{HA}$ and immunoblotting for Neurexins 1, 2, and 3 reveals similar level of interaction with HA-NL1FL (FL) and HA-NL1 $\Delta C(p=0.37, n=2$ independent IPs). HA, hemagglutinin epitope tag; $T M$, transmembrane domain; $G B$, gephyrin binding motif; WW, WW binding domain; PDZ, PDZ type II binding domain; Ctl, control. $\boldsymbol{B}$, Immunolabeling of HA shows localization patterns of the HA-NL1 constructs. Top, RSG, layers $\mathrm{II/III}$ and V of somatosensory cortex (SS1) and the hippocampus (Hip), arrowheads. Scale bar, 2 $\mathrm{mm}$. Lower left, Expression in the lateral amygdala (Amg), arrowhead. Scale bar, $300 \mu \mathrm{m}$. Lower right, Expression in specific strata of the hippocampus, arrowheads, SO, SR, and SLM. Scale bar, $200 \mu \mathrm{m}$. Dark areas reflect positive labeling. Sections analyzed were between -1.58 and $-2.30 \mathrm{~mm}$ bregma. C, D, Immunolabeling of PSD-95 (green), DAPI (blue), and HA epitope tag (red) for HA-NL1FL ( $($ ) and HA-NL1 $\Delta$ C (D). Scale bar, $200 \mu \mathrm{m}$. Quantification of both HA and PSD-95 intensity levels between SLM and SR. All intensities normalized to SR levels. $\boldsymbol{E}, \boldsymbol{F}$, Higher magnification and quantification of colocalization between $\mathrm{HA}$ and markers of excitatory (PSD95) versus inhibitory (GABA-AR $\alpha 1$ ) synaptic markers, HA-NL1FL mice $(\boldsymbol{E})$ and HA-NL1 $\Delta$ C mice $(\boldsymbol{F})$. Differences in colocalization patterns in all cases were not significant. All data shown are mean \pm SEM, significance determined by Student's $t$ test, $n=3$ paired littermates per test ( 3 double positives compared with 3 littermates of mixed single transgenic backgrounds).
}

presynaptic terminals, and PSD-95-positive puncta, a marker of mature postsynaptic densities. In HA-NL1FL mice, we found significant changes consistent with an increase in the prevalence of mature synaptic structures in SLM. The average area of Synapsin I puncta was increased relative to littermate controls (area: $158.5 \pm 5.4 \%$ vs $100 \pm 11.5 \%, p<0.01$; Fig. $2 C$ ). The average area of PSD-95 puncta was also enhanced without significant changes in intensity (area: $173.2 \pm 15.0 \%$ vs $100 \pm 16.1 \%, p<$ 0.01 ; Fig. $2 C$ ). These changes are consistent with an increase in the proportion of mature synaptic structures present. However, we did not observe a significant increase in the number of PSD-95 and Synapsin I-positive puncta per $100 \mu \mathrm{m}^{2}$ (123.5 $\pm 9.8 \%$ vs $100 \pm 13.5 \%, p>0.05)$. This corroborates the idea that HANLFL overexpression altered the state of the synapses present, but without a significant increase in synapse number in the SLM.

Remarkably, we observed distinct changes in Synapsin I and PSD-95 labeling in mice overexpressing HA-NL1 $\Delta$ C. We detected a significant decrease in the area of Synapsin I-positive puncta (area: $72.9 \pm 4.9 \%$ vs $100 \pm 5.8 \%, p<0.05$; Fig. $2 D$ ), without a significant decrease in the area of PSD-95 puncta $(70.1 \pm 6.12 \%$ vs $100 \pm 12.2 \%, p>0.05$; Fig. $2 D)$. Consistent with the changes in spine numbers, we also observed a significant increase in the density of PSD-95 puncta ( $137.8 \pm 4.4 \%$ vs $100 \pm$ $7.8 \%, p<0.05$; Fig. $2 D$ ). These results substantiate that in contrast to HA-NL1FL overexpression, HA-NL1 $\Delta \mathrm{C}$ overexpression increased the total number of synapses.

\section{HA-NL1FL and HA-NL1 $\Delta \mathrm{C}$ overexpression induce distinct changes in synaptic protein localization}

Studies characterizing the molecular composition of excitatory synapses across development have found activity-dependent changes in the prevalence of postsynaptic scaffolding molecules and glutamate receptors at distinct developmental stages (van Zundert et al., 2004; Petralia et al., 2005; Zheng et al., 2011). We therefore predicted that our manipulations of NL1 function should impact the postsynaptic scaffolding molecules and glutamate receptors associated with progression through development and synaptic maturation. We examined protein levels at synapses in both the HA-NL1FL and HA-NL1 $\Delta \mathrm{C}$ animals via quantitative immunoblotting of isolated synaptosome fractions from hippocampal tissue. Overexpression of NL1FL within restricted regions of the hippocampal formation led to a significant increase in synaptic levels of Synapsin I, SAP97, PICK1, and NR2A (Fig. 3A, Table 1). We observed no significant changes in the synaptic levels of PSD-95, nor the key inhibitory synaptic marker Gephyrin. In contrast, overexpression of HA-NL1 $\Delta \mathrm{C}$ resulted in enhanced levels of SAP102 and PSD-95, a modest increase in NR2B levels and a decrease in SAP97 (Fig. 3B, Tables 1, 2).Together, these changes indicate that there was an overall enrichment of synaptic proteins associated with mature features of excitatory synapses in the hippocampi of the HA-NL1FL animals, whereas HA-NL1 $\Delta$ C overexpression modulated proteins particularly relevant to developing synapses.

To confirm that the changes in synaptic protein levels were directly related to the level of expression of our transgenes, we analyzed immunostaining characteristics of a few key synaptic proteins in the SLM and SR of the hippocampus. We failed to identify any changes in measures of NR2B immunofluorescence within the hippocampus of HA-NL1-FL mice (Fig. 3C). However, the intensity and area of NR2B puncta specifically within the SLM of HA-NL1 $\Delta \mathrm{C}$ animals were enhanced relative to controls (Intensity: $136.8 \pm 3.8$ vs $100 \pm 9.4 \%, p<0.05$, Area: $143.5 \pm 7.4$ 
HA-NL1FL

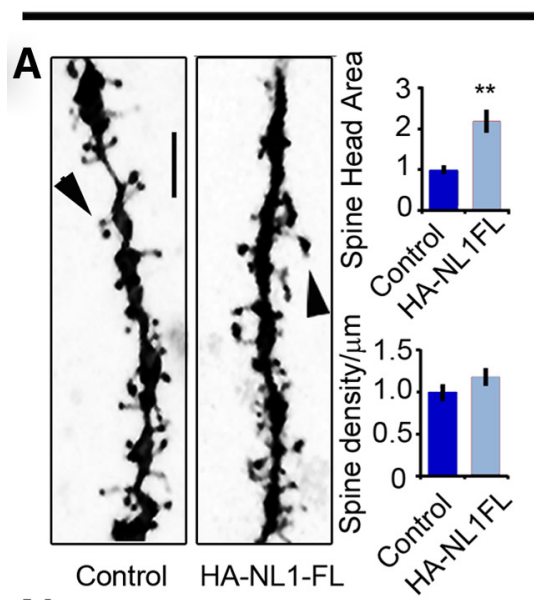

$A^{\prime}$
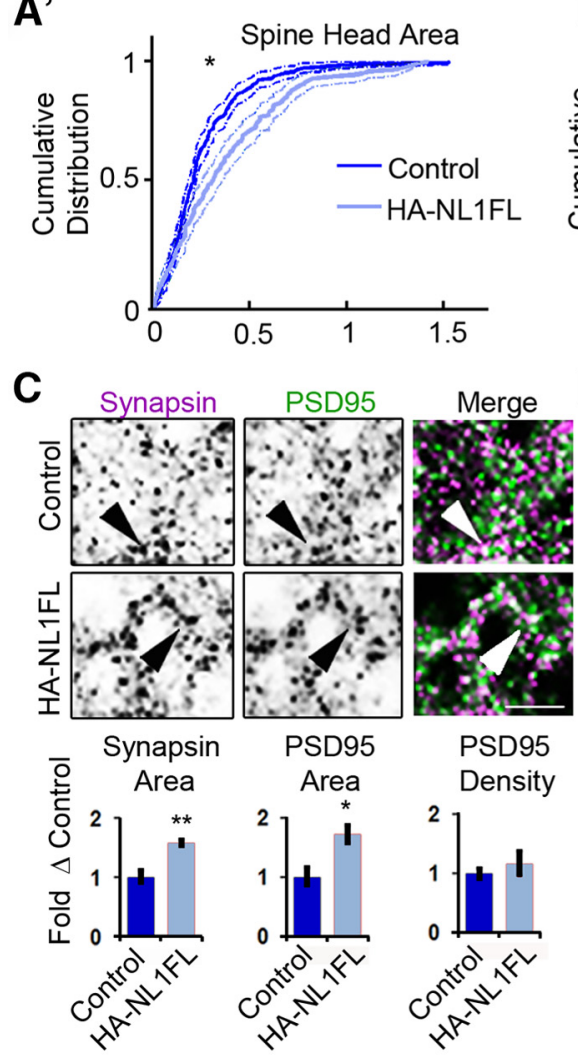

$\mathrm{HA}-\mathrm{NL} 1 \Delta \mathrm{C}$

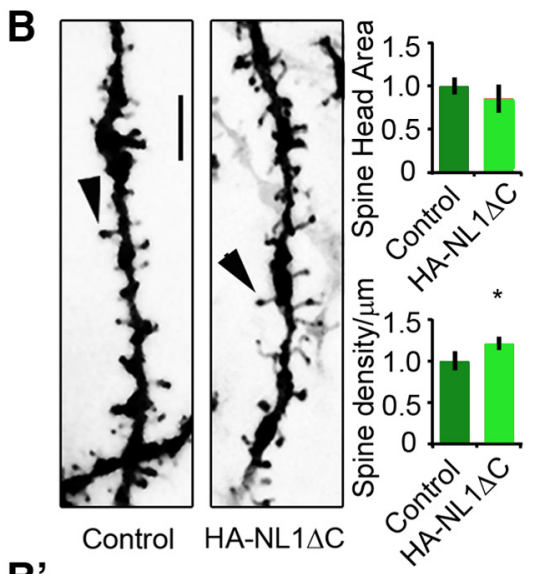

B'

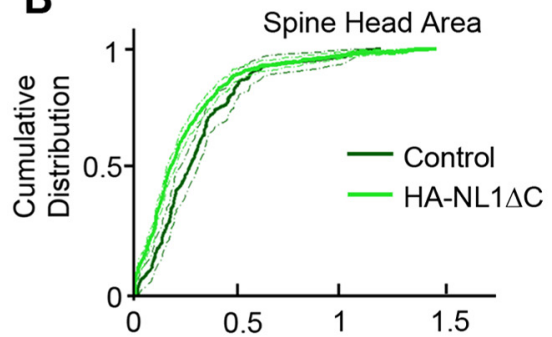

D

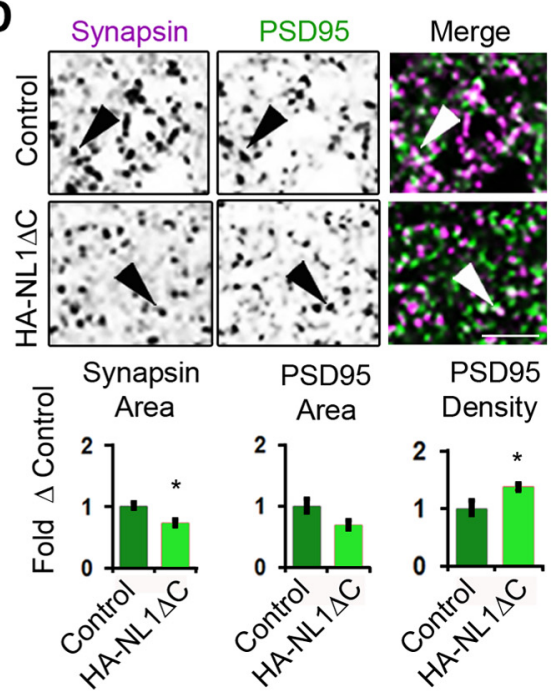

Figure 2. NL1 intracellular signaling regulates the morphological characteristics of spines and synapses in SLM. A, B, Representative images of dendritic spine segments labeled with Dil of control versus HA-NL1FL mice $(\boldsymbol{A})$ and control versus HA-NL1 $\Delta C$ mice $(\boldsymbol{B})$. Scale bar, $2.5 \mu \mathrm{m}$. The mean spine head area was increased for only the HA-NL1FL mice, while spine density was only increased in the HA-NL1 $\Delta$ C mice ( $p<0.05$, Student's $t$ test, $n=36$ pairs). $\boldsymbol{A}^{\prime}, \boldsymbol{B}^{\prime}$, Cumulative distributions with confidence intervals of spine head sizes across 36 dendritic segments from each transgenic group compared with their controls. Significant differences in the distributions were tested with the Kolmogorov-Smirnov test, $p<0.00001$ for controls versus HA-NL1FL mice and $p=0.077$ for controls versus HA-NL1 $\Delta C$ mice. C, $D$, Representative images and quantification of Synapsin I and PSD-95positive puncta characteristics of controls versus HA-NL1FL mice $(\boldsymbol{C})$ and controls versus HA-NL1 $\Delta C$ mice $(\boldsymbol{D})$. Areas positive for immunostaining are black. The merge image is shown in color, with Synapsin I in magenta, PSD-95 in green and areas of overlap appearing white. Arrows highlight Synapsin I and PSD-95 colocalization. Scale bar, $2.5 \mu \mathrm{m}$. All data are shown mean \pm SEM. Student's $t$ test performed in all cases unless otherwise noted, ${ }^{*} p<0.05,{ }^{* *} p<0.01, n=4$ pairs ( 4 double positive transgenics in each group or 4 mixed single transgenic controls).

vs $100 \pm 8.3, p<0.01$; Fig. $3 D$ ). We observed no significant difference of NR2B staining within the SR (Intensity: $130.8 \pm$ 11.5 vs $100 \pm 7.6, p>0.05$, Area: $132.2 \pm 16.9 \%$ vs $100 \pm 7.0 \%$, $p>0.05$ ), nor the stratum lucidum of CA3 (Intensity: $100 \pm$ $9.6 \%$ vs $111.3 \pm 7.1 \%, p>0.05)$.

Immunolabeling with an antibody to all three Shank family members (panShank) revealed that levels of one or all members were specifically increased in the SLM of HA-NL1FL mice relative to controls (Intensity: $135.2 \pm 1.6 \%$ vs $100 \pm 2.7 \%$, respectively, $p<0.01$, Area: $131.7 \pm 18.9 \%$ vs $100 \pm 12.6 \%, p<0.05$; Fig. $3 E$ ). There was no significant change in panShank labeling in HA-NL1 $\Delta \mathrm{C}$ mice (Fig. $3 F$ ). Our results demonstrate that our manipulations induced the largest changes in regions with higher levels of transgene expression, specifically, the SLM. Therefore, given our biochemical data and the clear differences between HA-NL1FL and HA-NL1 $\Delta \mathrm{C}$ mice, we conclude that the intracellular C-terminal region that is missing from the $\mathrm{HA}$ $\mathrm{NL} 1 \Delta \mathrm{C}$ protein is required for the additional recruitment of Synapsin1, SAP97, PICK1, and Shank family members observed when NL1FL is overexpressed. Moreover, the differences between overexpressing NL1FL and NL1 $\Delta \mathrm{C}$ modulate NMDAR subunit composition in vivo. Such activities have been implicated in the normal maturation of excitatory synapses over development.

\section{Discrete changes in synaptic}

transmission characterize HA-NL1FL

and HA-NL1 $\Delta \mathrm{C}$ overexpressing mice

Given the observed changes in morphology and biochemistry, and previous reports of NL1's influence on NMDARs, we specifically compared the ratio of NMDAR to AMPAR-mediated synaptic transmission, NMDAR decay kinetics, and paired-pulse facilitation in the SLM and SR. AMPAR and NMDAR-mediated EPSCs in CA1 pyramidal cells were elicited by stimulating either perforant path (PP) fibers that innervate SLM or Schaffer collaterals (Sch) that innervate SR in the acute hippocampal slice preparation (see Materials and Methods). HA-NL1FL overexpression in both the PP and in the Sch-CA1 synapses, led to significant enhancement in the NMDAR/AMPAR ratio relative to controls $(0.38 \pm 0.03, n=13$, HA-NL1FL vs $0.20 \pm 0.02, n=8$; controls, $p=6.66 \times 10^{-5}$, at PP-CA1; $0.13 \pm$ $0.02, n=10$; HA-NL1FL vs $0.08 \pm 0.007$, $n=9$; Controls, $p=0.011$ at Sch-CA1; Fig. $4 A, B)$. Note that the ratio was only significantly different between the HANL1FL mice and HA-NL1 $\Delta \mathrm{C}$ mice in the $\operatorname{SLM}(0.38 \pm 0.03, n=13$, HA-NL1FL vs $0.22 \pm 0.02, n=10$, HA-NL1 $\Delta$ C, $\left.p=1.72 \times 10^{-4}\right)$. Consistent with our other findings, HA-NL1 $\Delta$ C failed to induce a change in the NMDAR/AMPAR ratio in both SLM and SR. Surprisingly, we also found that overexpression of HA-NL1FL led to longer NMDAR decay kinetics 
HA-NL1FL
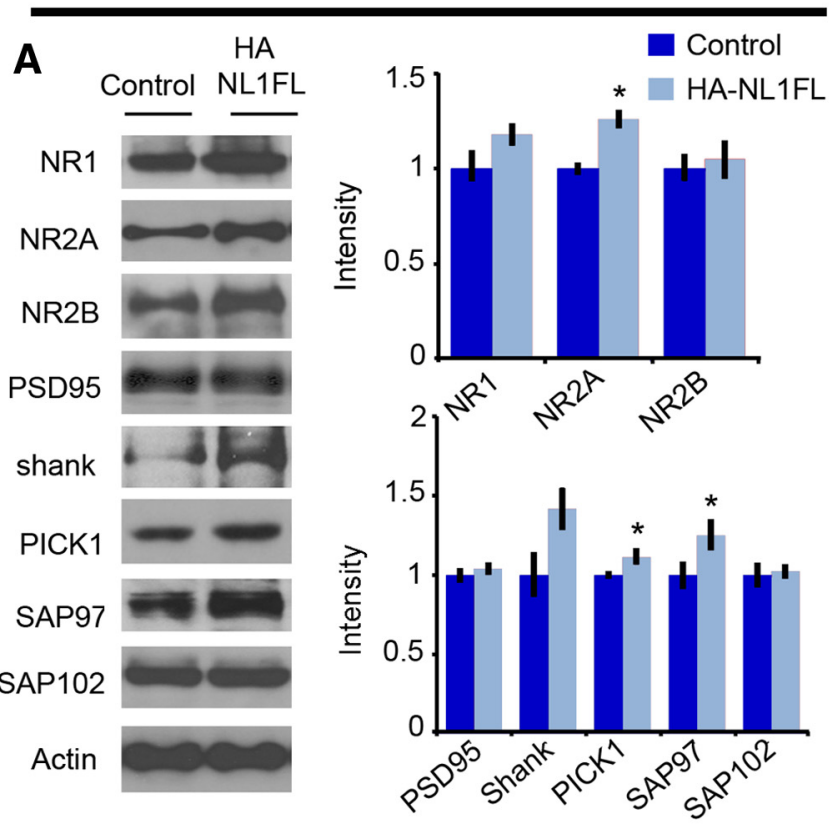

C
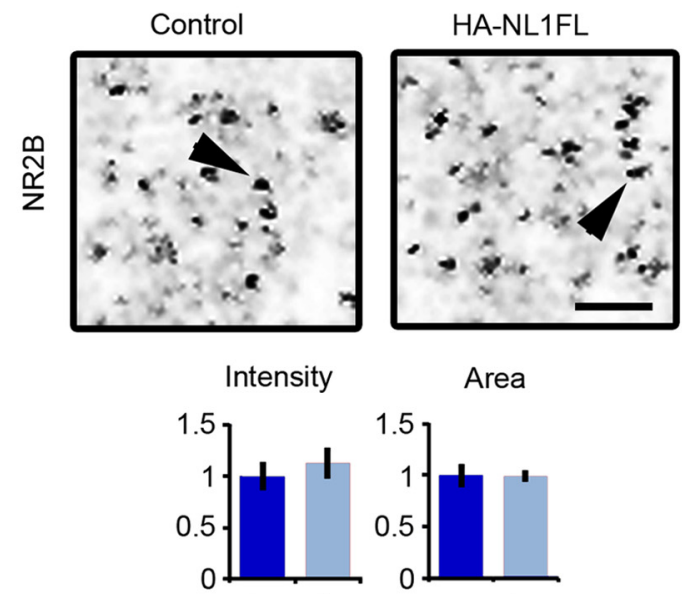

Area
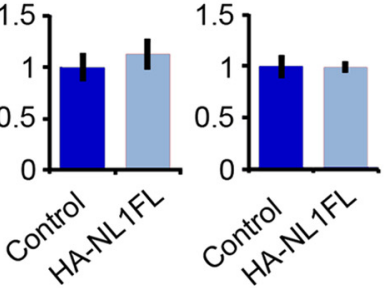

E
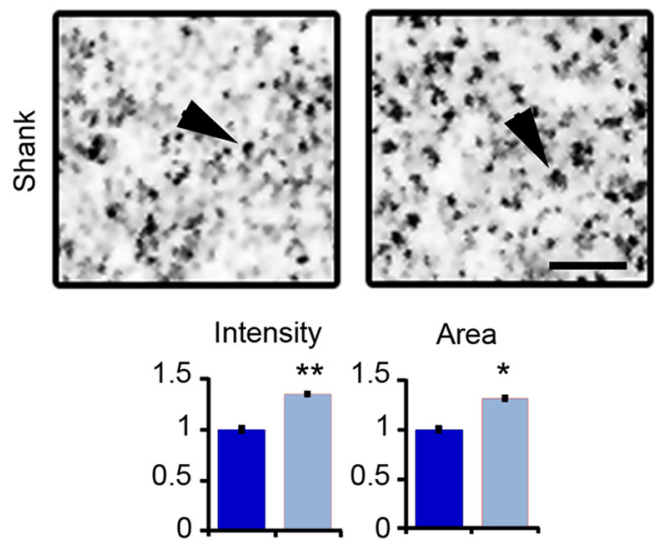

Area
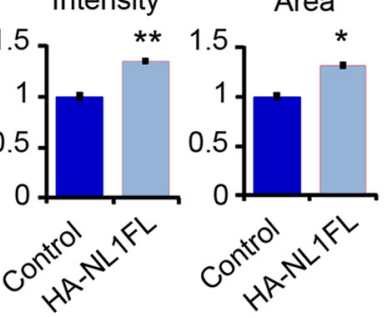

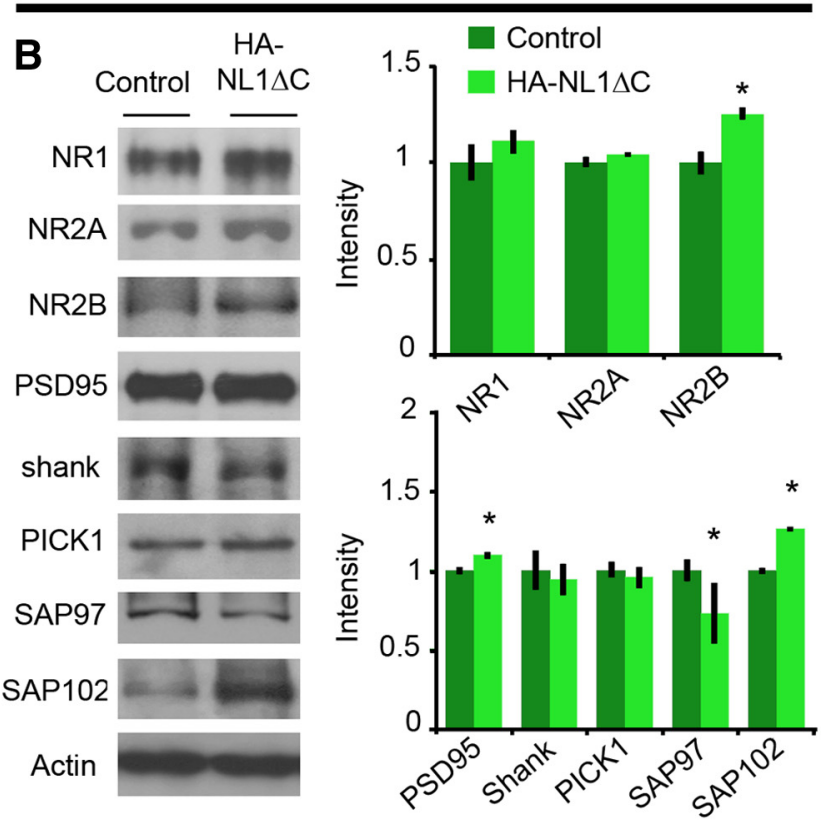

D

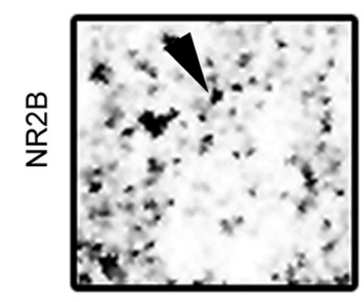

Intensity
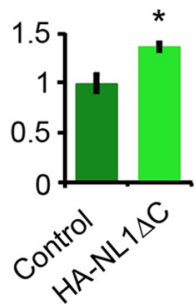

$\mathbf{F}$

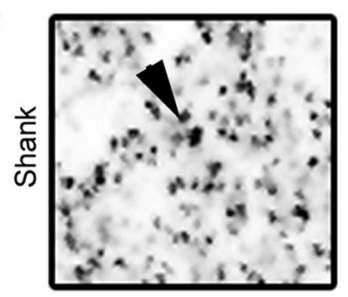

Intensity

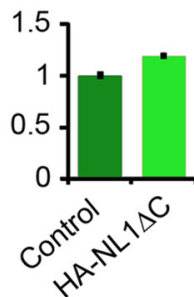

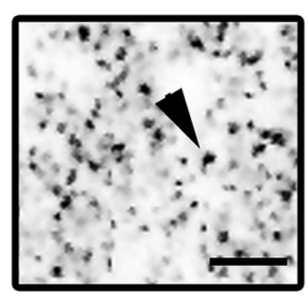

HA-NL $1 \Delta \mathrm{C}$

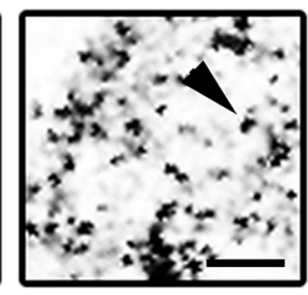

Area

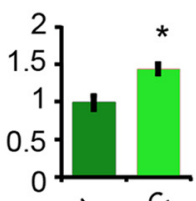

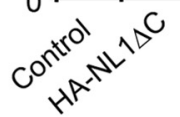

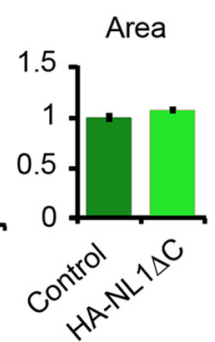

Figure 3. Distinct changes in synaptic protein composition in HA-NL1FL versus HA-NL1 $\Delta$ C mice. Representative Western blots of synaptosomal fractions from the hippocampus of controls versus HA-NL1FL mice $(\boldsymbol{A})$ and controls vs HA-NL1 $\Delta C$ mice $(\boldsymbol{B})$. Lanes are aligned to show the same mouse from each group, with the mean intensity from four individuals plotted on the right normalized to control levels. A subset of the total blots performed showing the significant differences are shown here, detailed statistics and additional blot shown in Tables 1 and 2. (Figure legend continues.) 
Table 1. Differences in protein expression levels in synaptosome fractions between HA-NL1FL and HA-NL1 $\Delta C$ mice

\begin{tabular}{llrlll}
\hline Protein & $\% \Delta$ & SEM & $p$ value & Effect size & Cohen's \\
\hline HA-NLIFL & & & & & \\
NL1 & 183.00 & 1.23 & $0.0004^{* *}$ & 0.96 & 7.93 \\
NL3 & 155.68 & 56.80 & 0.2372 & 0.75 & 2.29 \\
NR1 & 118.26 & 5.00 & 0.0610 & 0.76 & 2.33 \\
NR2A & 126.48 & 3.73 & $0.0161^{*}$ & 0.89 & 3.80 \\
NR2B & 109.27 & 10.36 & 0.7633 & 0.48 & 1.08 \\
GluR1 & 111.98 & 4.55 & 0.0518 & 0.80 & 2.71 \\
GluR2 & 120.86 & 5.74 & 0.1127 & 0.86 & 3.31 \\
PSD-95 & 103.96 & 2.83 & 0.4515 & 0.57 & 1.37 \\
PanShank & 141.98 & 12.23 & 0.1035 & 0.85 & 3.29 \\
Gephyrin & 108.17 & 7.12 & 0.2058 & 0.51 & 1.19 \\
PICK1 & 111.49 & 4.04 & $0.0370^{*}$ & 0.88 & 3.81 \\
SAP97 & 125.33 & 8.71 & $0.0322^{*}$ & 0.85 & 3.17 \\
SAP102 & 102.26 & 3.35 & 0.4964 & 0.19 & 0.39 \\
SNAP25 & 107.86 & 2.69 & 0.4745 & 0.53 & 1.24 \\
Synapsin1 & 119.35 & 2.67 & $0.0185^{*}$ & 0.97 & 7.56 \\
VGLUT1 & 101.17 & 1.51 & 0.0799 & 0.39 & 0.85 \\
\hline
\end{tabular}

Summary statistics for levels of all synaptic proteins analyzed from hippocampal synaptosome fractions from controls versus HA-NL1FL mice. Significance was determined with Student's $t$ test, ${ }^{*} p<0.05$ and ${ }^{* *} p>0.01, n=4$ animals in each group.

Table 2. Differences in protein expression levels in synaptosome fractions between HA-NL1FL and HA-NL1 $\Delta C$ mice

\begin{tabular}{lrrlrr}
\hline Protein & $\% \Delta$ & SEM & $p$ value & Effect size & Cohen's \\
\hline HA-NL1 $\Delta$ C & & & & & \\
NL1 & 198.43 & 5.73 & $0.0021^{* *}$ & 0.99 & 15.88 \\
NL3 & 108.73 & 0.94 & 0.1380 & 0.63 & 1.65 \\
NR1 & 111.18 & 5.12 & 0.1481 & 0.62 & 1.56 \\
NR2A & 104.31 & 0.27 & 0.1732 & 0.78 & 2.48 \\
NR2B & 125.34 & 2.46 & $0.0443^{*}$ & 0.96 & 6.51 \\
GluR1 & 148.80 & 7.49 & 0.2250 & 0.83 & 2.98 \\
GluR2 & 116.56 & 4.04 & 0.1018 & 0.85 & 3.16 \\
PSD-95 & 109.92 & 0.87 & 0.1834 & 0.97 & 7.37 \\
PanShank & 94.61 & 8.89 & 0.7536 & -0.25 & -0.52 \\
Gephyrin & 96.73 & 1.17 & 0.1823 & -0.78 & -2.65 \\
PICK1 & 95.85 & 5.67 & 0.6600 & -0.37 & -0.79 \\
SAP97 & 73.14 & 18.44 & $0.0213^{*}$ & -0.70 & -1.95 \\
SAP102 & 126.59 & 0.40 & $0.0316^{*}$ & 0.99 & 44.66 \\
SNAP25 & 105.48 & 0.96 & $0.0065^{* *}$ & 0.92 & 4.65 \\
Synapsin1 & 112.16 & 1.78 & 0.0782 & 0.81 & 2.75 \\
VGLUT1 & 98.99 & 0.73 & 0.2849 & -0.52 & -1.22 \\
\hline
\end{tabular}

Summary statistics for levels of all synaptic proteins analyzed from hippocampal synaptosome fractions from controls versus HA-NL1 $\Delta$ C mice. Significance was determined with Student's $t$ test, ${ }^{*} p<0.05$ and ${ }^{*} p>0.01, n=4$ animals in each group.

at PP-CA1 synapses ( $156.44 \pm 10.67 \mathrm{~ms}, n=10$, HA-NL1FL vs $118.39 \pm 7.93 \mathrm{~ms}, n=6$, Controls, $p=0.02$; Fig. $4 C$ ). Overexpression of HA-NL1 $\Delta \mathrm{C}$ did not induce this change $(115.04 \pm 14.58 \mathrm{~ms}$, $n=7$, HA-NL1 $\Delta$ C vs $118.39 \pm 7.93 \mathrm{~ms}, n=6$, Controls, $p=0.85$ ). In contrast, we found no significant alteration between genotypes in NMDAR EPSC decay kinetics at Sch-CA1 synapses showing that this phenotype is specific to the SLM (Fig. 4E).

(Figure legend continued.) Representative images of a $36 \mu \mathrm{m}^{2}$ region of SLM from sectioned tissue immunolabeled for NR2B from controls versus HA-NL1FL mice $(\boldsymbol{C})$ and controls versus HA-NL1 $\Delta C$ mice $(\boldsymbol{D})$. Average intensity and area of puncta from the four individuals from each group is graphed below. Scale bar, $2 \mu \mathrm{m}$. Arrows highlight puncta for comparison. Representative images of a region of SLM labeled for panShank from controls versus HA-NL1FL mice $(\boldsymbol{E})$ and controls versus HA-NL1 $\Delta C$ mice $(\boldsymbol{F})$. Scale bar, $2 \mu \mathrm{m}$, and arrows highlight puncta for comparison. Significance was determined with Student's $t$ test, all data are shown mean \pm SEM, ${ }^{*} p<0.05,{ }^{* *} p<0.01, n=4$ pairs ( 4 mice in each group).
To examine whether our manipulations could also affect presynaptic function, we measured paired-pulse facilitation. We found no significant differences in this measure between any group (Fig. $4 D, F)$. Finally, to quantify the contribution of NR2B to PP-CA1 synaptic transmission in HA-NL1 $\Delta$ C mice, we tested the effect of the selective NR2B antagonist Ro 25-6981 on NMDAR-mediated transmission in the SLM (see Materials and Methods). Application of Ro $(500 \mathrm{nM})$ reduced NMDAR transmission, but this reduction was not significantly different between groups (HA-NL1 $\Delta$ C $80.5 \pm 1.95 \%$ of baseline, $n=8$; Control $83.8 \pm 2.0 \%$ of baseline, $n=6 ; p=0.23$, data not shown). The modest increase in NR2B localization in the SLM of the HA-NL1 $\Delta$ C mice (Fig. $3 B, D$ ) did not result in a specific and significant increase in NR1/NR2B containing heterodimers, but may have instead increased the number of NR1/NR2A/NR2B heterotrimers, which are less sensitive to Ro (Tovar and Westbrook, 1999).

We next investigated whether overexpression of HA-NL1FL and HA-NL1 $\Delta \mathrm{C}$ could affect the induction of NMDAR-dependent LTP at PP-CA1 synapses (PP LTP) (see Materials and Methods). We found no significant difference in the magnitude of PP LTP in hippocampal slices prepared from HA-NL1FL and HA-NL1 $\Delta$ C mice compared with interleaved control slices (HA-NL1FL $126.27 \pm$ $3.41 \%$ of baseline, three mice, nine slices; Control $131.92 \pm 5.22 \%$ of baseline, three mice, seven slices; HA-NL1FL vs Control $p=0.3616$; HA-NL1 $\Delta$ C $131 \pm 5.16 \%$ of baseline, three mice, eight slices; Control $136.45 \pm 6.70 \%$ of baseline, three mice, nine slices; HA-NL1 $\Delta \mathrm{C}$ vs Control $p=0.5515$; Fig. $4 G, H)$. PP LTP was associated with a significant reduction in PPR (HA-NL1FL $1.45 \pm 0.024$ before, $1.38 \pm 0.02$ after $p=0.00045$; Control $1.44 \pm 0.053$ before, $1.36 \pm$ 0.051 after, $p=0.00031$; HA-NL1 $\Delta$ C $1.40 \pm 0.043$ before, $1.34 \pm$ 0.039 after, $p=0.00172$; Control: $1.38 \pm 0.028$ before, $1.31 \pm 0.021$ after, $p=0.00058$; Fig. $4 G, H$, insets). This result is consistent with a previous report that an important component of this form of plasticity is expressed presynaptically (Ahmed and Siegelbaum, 2009). Collectively, our functional analysis supports the idea that NL1FL overexpression affected NMDAR-mediated synaptic transmission, and that this effect requires the NL1 C-terminal region as overexpressing NL1 $\Delta \mathrm{C}$ yielded no significant physiological changes in our measures.

We primarily investigated synaptic changes in the hippocampus in our transgenic animals as we saw the strongest expression levels within a specific target layer in this structure. However, our transgenes were also expressed throughout other forebrain structures, including specific layers within primary sensory cortices (Fig. 1). Moreover, our data and others show that overexpression of NL1FL reliably impacts synaptic spine morphology, while our data additionally shows that HA-NL1- $\Delta$ C overexpression impacts spine number. Both of these synaptic features, abnormal spine number and morphology, have been observed in temporal lobe cortex in humans with ASD (Hutsler and Zhang, 2010; Penzes et al., 2011). As this region of cortex in humans processes auditory information, we additionally assayed for changes in sensory-evoked responses in primary auditory cortex in our mice. We could not detect a significant change in the relationship between neuronal firing rates and stimulus strength in the auditory cortex of HA-NL1FL mice (Fig. 5A). However, we found a significant shift in the threshold for evoking sensory responses in the HA-NL1 $\Delta$ C mice as compared with controls (Fig. 5B). Basic auditory responses such as the startle reflex were unaffected (data not shown). Interestingly, such a shift in the threshold for sensory-evoked responses is a characteristic developmental milestone in the auditory cortex, where a decrease in the threshold to elicit a change in firing rate accompanies developmental progres- 
sion (Moore and Irvine, 1979; de VillersSidani et al., 2007). Thus, our findings suggest that the changes elicited by NL1 $\Delta$ C overexpression in cortex correlate to developmentally relevant changes in sensory-evoked responses in at least the primary auditory cortex, while the NL1FL overexpression effects were unable to bring about a change in this measure.

\section{Overexpression of HA-NL1FL versus \\ HA-NL1 $\Delta$ C differentially impact behavioral performance in learning and memory tasks}

Distinct behavioral differences between the HA-NL1FL mice and the HA-NL1 $\Delta \mathrm{C}$ mice would argue that the intracellular domain of NL1 that is removed in NL1 $\Delta \mathrm{C}$ is key in modulating changes to synaptic function and behavior when NL1 is overexpressed. Given that overexpression and knock-out of NL1 has been found to impact explicit learning and memory behaviors as assessed by the Morris water maze (Blundell et al., 2010; Dahlhaus et al., 2010), we first characterized the behavior of our transgenic mice in the same task. Importantly, we directly compared the behavior of both lines and their respective controls in the same experiment.

Specific aspects of performance in the water maze task were different between the HA-NL1FL and HA-NL1 $\Delta \mathrm{C}$ mice, while swim speed and thigmotaxic behavior were not significantly different between all groups throughout training (Fig. $6 K$; not shown). First, we noticed that $\mathrm{HA}-\mathrm{NL} 1 \Delta \mathrm{C}$ overexpressing mice learned to reach a visually cued platform in less time and with less distance traveled than all the other groups on the first day of training (main effect of genotype on latency: $F_{(3,74)}=4.14, p<0.01$, main effect of day: $F_{(1,74)}=101.62, p<0.001$, no significant effect of genotype $\times$ day interaction; Fig. $\left.6 A, A^{\prime}\right)$. Second, during acquisition training, only the HA-NL1FL overexpressing mice took significantly more time and distance over more days to learn the target location relative to all other groups (main effect of genotype on latency: $F_{(3,259)}=$ 14.26, $p<0.001$, main effect of day: $F_{(6,259)}=38.63, p<0.001$, main effect of genotype $\times$ day interaction: $F_{(18,259)}=$ 1.67, $p<0.05$; Fig. $\left.6 B, B^{\prime}\right)$. These data support the idea that the two transgenic lines exhibit distinct learning behaviors during the acquisition phases of the Morris water maze task.

Analysis of probe trial performance after acquisition training also revealed differences between the HA-NL1FL and the
A

Perforant Path-CA1 (PP)
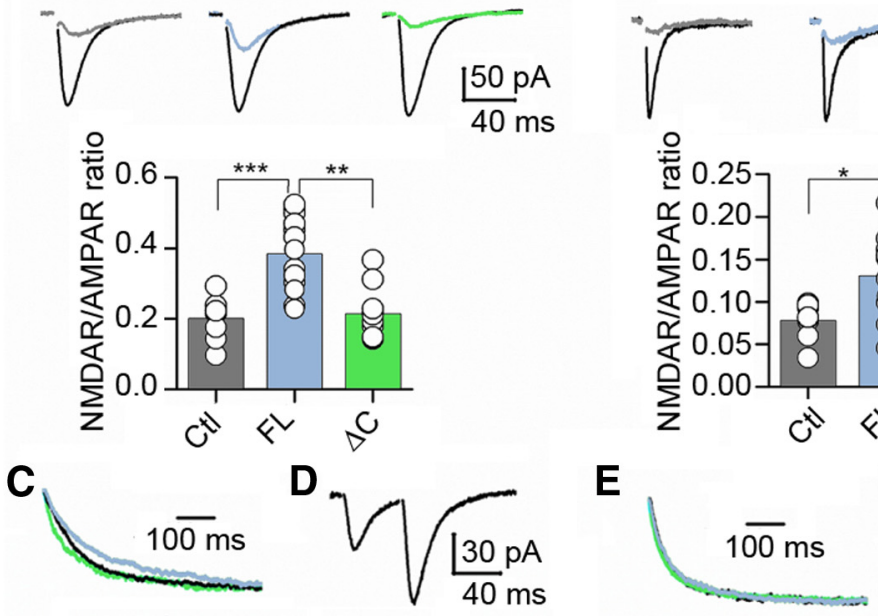
(Sch)

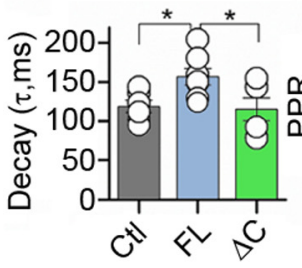

$3-10$
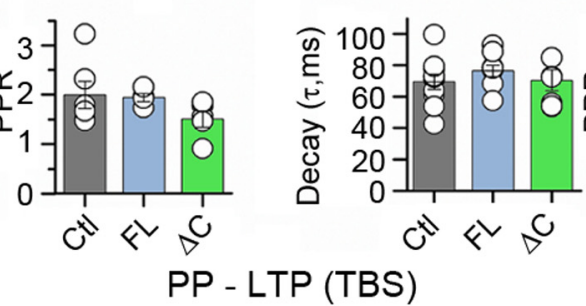

$F$

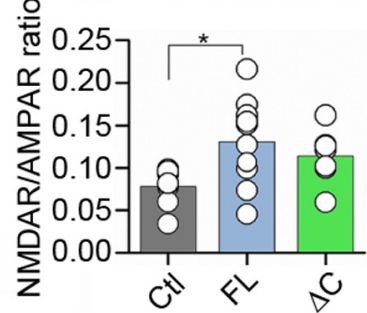
$\frac{40}{40} \mathrm{pA}$
G HA-NL1FL
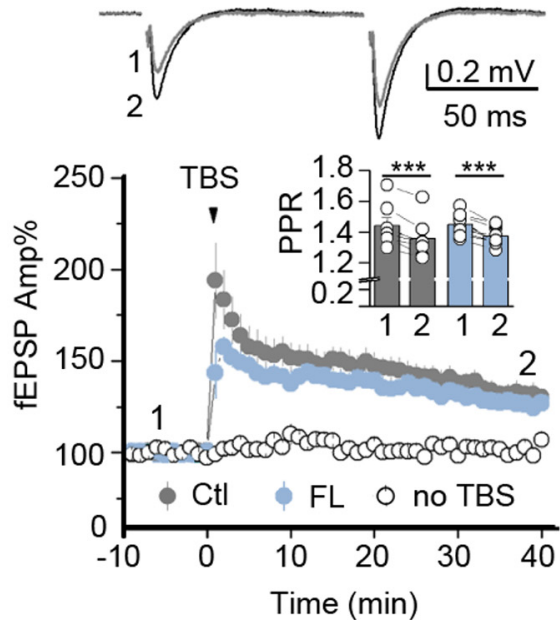

H $\mathrm{HA}-\mathrm{NL} 1 \triangle \mathrm{C}$
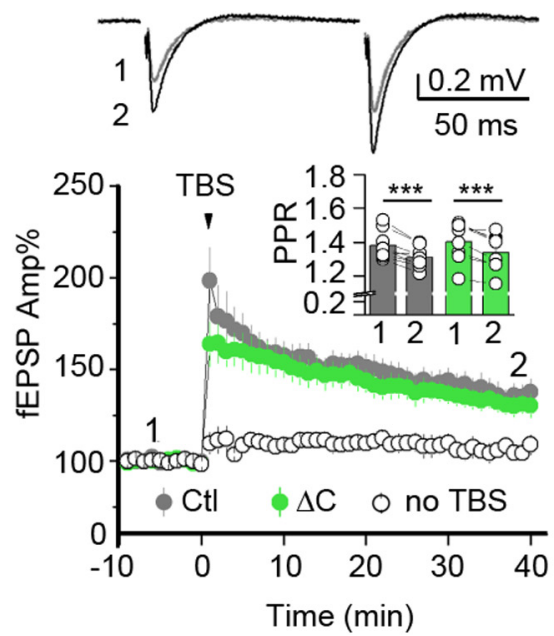

Figure 4. Manipulations of NL1 specifically affect NMDAR-mediated synaptic transmission in hippocampus. Comparisons of NMDAR-mediated synaptic transmission at PP-CA1 versus Sch-CA1 synapses. A, AMPAR and NMDAR-mediated EPSCs were measured from the same CA1 neuron $\left(V_{\mathrm{h}}=-60 \mathrm{mV}\right)$ in the continuous presence of $100 \mu \mathrm{m}$ picrotoxin for AMPAR-EPSCs or picrotoxin and $10 \mu \mathrm{m}$ NBQX for NMDAR-EPSCs. Representative AMPAR-EPSC traces (black) and NMDAREPSCs (representative colors) are shown on top, $N \geq 7$ cells in each group (13 cells max). $\boldsymbol{B}$, Similar measures taken at the Sch. C, Decay kinetics of NMDAR-EPSCS. NMDAR-EPSCs were measured at $+30 \mathrm{mV}$ in the presence of picrotoxin and NBQX, $N \geq 6$ (max 10). Representative traces are shown at top, and group averages are shown in a graph below. $\boldsymbol{D}$, Paired-pulse ratio (PPR) of AMPA EPSCs was measured at $-60 \mathrm{mV}, 50 \mathrm{~ms}$ apart in the PP revealing no differences between transgenic lines and controls. $\boldsymbol{E}$, No differences were found in decay kinetics at the $S c h$, and $(\boldsymbol{F})$ no differences were found in PPR of AMPAR EPSCs measured at $-60 \mathrm{mV}, 40 \mathrm{~ms}$ apart, $N \geq 4(\max 9)$. $\boldsymbol{G}, \boldsymbol{H}$, LTP at the PP-CA1 synapse. Field EPSPs were measured in presence of $100 \mu \mathrm{m}$ picrotoxin and $3 \mu \mathrm{M}$ CGP-55845. Representative traces were taken at time points ( 1 and 2) and are shown at top. Summary plots showing PP-LTP induced by TBS in Controls ( $\mathrm{Ctl}, 3$ mice, 7 slices $(\boldsymbol{G})$ and 9 slices $(\boldsymbol{H})$ ), HA-NL1 $\Delta C$ ( $\Delta C, 3$ mice; 8 slices) and HA-NL1FL (FL, 3 mice, 9 slices) mice. All experiments included an independent, PP-CA1 naive pathway ("no TBS"). Insets, Summary of PPR before (1) and after (2) LTP induction for FL and $\Delta$ C mice. All data are presented as mean \pm SEM, and traces are illustrated as averages of $10-15$ individual responses. Stimulus artifacts were digitally removed. ${ }^{*} p<0.05,{ }^{* *} p<0.01,{ }^{* * *} p<0.001$. 

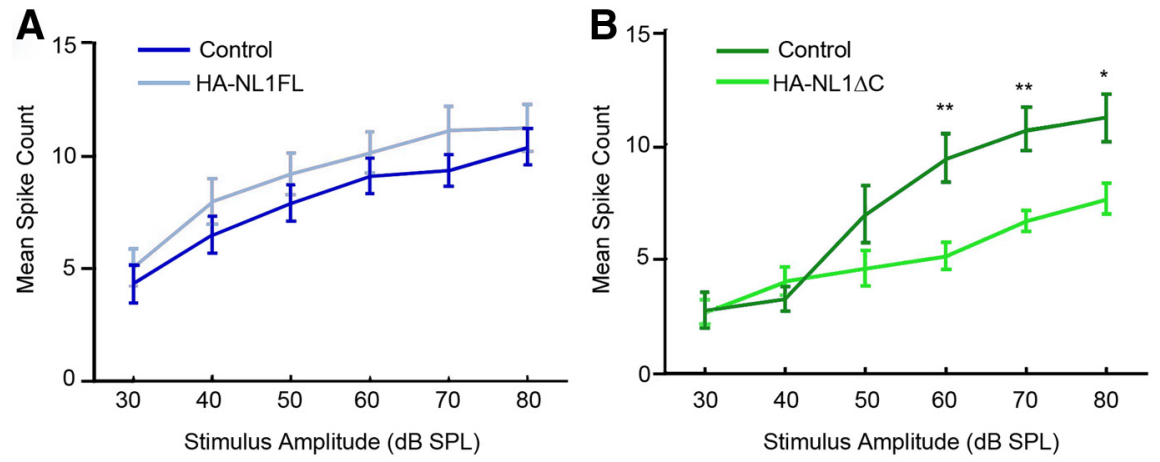

crosses: $3.02 \pm 0.51$ vs $1.31 \pm 0.34 p<0.05)$. Together, this suggests that the HA-NL1 $\Delta \mathrm{C}$ mice abandoned searching the former location faster than all other groups during the first day of reversal training, whereas NL1FL mice persisted in searching the former location longer than all other groups. The enhanced perseverance observed in the HANL1FL mice relative to the control groups suggests a significant decrease in flexibility when this protein is overexpressed. These important differences highlight that overexpression of HA-NL1 $\Delta$ C brought about distinct gain of function effects as opposed to the specific perturbations in behavior brought about by HA-NL1FL overexpression in this task.

To further interpret how the changes in water maze behavior related to learning and

HA-NL1 $\Delta \mathrm{C}$ mice with respect to recall-related behaviors. The HA-NL1 $\Delta \mathrm{C}$ mice were the only ones to spend a significantly reduced amount of time in the target quadrant $(38.11 \pm 2.64 \%$, HA-NL $1 \Delta$ C mice vs $53.58 \pm 4.54 \%$, controls, $p<0.001$; Fig. $6 C, D)$. Concurrently, there was also a significant increase in dwell time spent by the HA-NL1 $\Delta \mathrm{C}$ mice in the quadrant opposite to the target location relative to their controls $(19.57 \pm 1.65 \%$ vs $9.18 \pm 1.75 \%, p<0.001)$ and relative to the HA-NL1FL mice $(19.57 \pm 1.65 \%$ vs $10.68 \pm 1.62 \%, p<0.001)$. Interestingly, the HA-NL1 $\Delta$ C mice also traveled a significantly shorter distance to their first cross of the former platform location relative to their controls $(\Delta \mathrm{C}$ controls, $53.78 \pm 8.39 \mathrm{~cm}, p<0.0167)$ and there were no significant differences in the distances traveled between the two control groups $(p>0.05)$. This suggests enhanced flexibility in search strategy. In contrast, the HA-NL1FL mice traveled more distance before making their first cross of the former platform location relative to the HA-NL1 $\Delta$ C mice $(74.63 \pm 12.42$ cm vs $21.31 \pm 2.75 \mathrm{~cm}, p<0.01$; Fig. $6 E^{\prime}$ ), and made significantly fewer crosses of the former platform location relative to their controls (2.75 \pm 0.39 vs $4.10 \pm 0.24, p<0.01$; Fig. $6 E)$ and relative to the HA-NL1 $\Delta \mathrm{C}$ mice $(4.23 \pm 0.34, p<0.01)$, despite comparable dwell time in the correct area. Therefore, the HANL1FL mice presented classical deficits associated with impaired recall performance, whereas the HA-NL1 $\Delta \mathrm{C}$ mice showed a distinct set of behavioral traits that suggested subtle enhancements in learning and increased flexibility in search strategy.

As further evidence for change in behavioral flexibility in the water maze task in our transgenic lines, we also found differences in behavior during reversal training (main effect of genotype: $F_{(3,111)}=15.32, p<0.001$, main effect of day: $F_{(2,111)}=35.16$, $p<0.001$, main effect of genotype $\times$ day interaction: $F_{(6,111)}=$ $0.41, p>0.05$; Fig. $\left.6 F, F^{\prime}\right)$. The number of crosses of the former platform location was reduced in the HA-NL1 $\Delta \mathrm{C}$ mice relative to controls $(2.3 \pm 0.40$ crosses vs $3.89 \pm 0.3$ crosses, $p<0.01)$, and relative to the HA-NL1FL mice $(3.29 \pm 0.24, p<0.0167$; Fig. $6 H$ ). Similarly, dwell time in the quadrant that formerly contained the platform was significantly lower for the HA-NL1 $\Delta \mathrm{C}$ mice relative to their controls $(25.97 \pm 3.70 \%$ vs $39.76 \pm 3.99 \%$, $p<0.0167$; Fig. $6 H^{\prime}$ ), and relative to the HA-NL1FL mice (HANL1FL mice: $40.88 \pm 5.27 \%, p<0.025$; Fig. $\left.6 H^{\prime}\right)$. Moreover, the HA-NL1FL mice displayed increased dwell time in the former target quadrant and an increased number of crosses of the former platform location than their controls on the second day of reversal training (percentage dwell time: $33.31 \pm 4.23$ vs $18.24 \pm 3.98 \%, p<0.05$, memory we also used the object recognition task. Only the HANL1FL mice displayed a lack of preference for the novel object after an hour delay between object familiarization and re-exposure (49.9 $\pm 5.4 \%$ time with new object vs $50 \%$ chance performance, $p>$ 0.05 , Wilcoxon signed rank test, $n=10$ pairs; Fig. $6 I$ ). This result is consistent with a deficit in learning and recall behavior. However, we observed impairment for recall after a single exposure with a delay of $24 \mathrm{~h}$ in the HA-NL1 $\Delta \mathrm{C}$ mice (Novelty preference: $49.9 \pm 8.8 \%$ vs $50 \%$ chance performance, $p<0.05, n=10$ pairs, Wilcoxon signed rank test; Fig. $6 J$ ). This suggested that object recognition learning over the short term occurred similarly to controls in this task, but that the single trial learning was less stable over $24 \mathrm{~h}$ in this group. The same differences were found in a spatial version of the object recognition task (data not shown), suggesting that these changes in recall behavior generalized to multiple forms of explicit memory formation.

Overall, the data gathered on learning and memory behaviors between the HA-NL1FL and HA-NL1 $\Delta \mathrm{C}$ mice suggest distinct differences in how the two lines of mice perform these tasks. In particular, the data reflect impaired learning and flexibility in the FL mice, yet enhanced flexibility in the $\Delta \mathrm{C}$ mice with a weak deficit in recognition memory after a $24 \mathrm{~h}$ delay.

\section{Only overexpression of NL $\Delta \mathrm{C}$ affects social behavior}

NL1 function has also been linked to social behavior in studies where genetic manipulations were ubiquitous throughout the brain (Blundell et al., 2010). Moreover, it is unclear which neural circuits may process social information (Insel and Fernald, 2004). We therefore studied whether our manipulations could also impact social behavior. First, the three-chambered social preference test allowed us to gauge basic social preferences (Moy et al., 2004). Typically, mice of our background strain prefer social interaction over that with an object, and interaction with a novel partner over that of a familiar (Moy et al., 2004). Surprisingly, we observed no significant differences in the behavior of the HANL1FL mice relative to the controls in any phase of this task (Fig. $7 A-C)$. Both the HA-NL1FL mice and their controls showed significant preferences for social interaction $(p<0.01$; Fig. $7 A)$ and social novelty $(p<0.01$; Fig. $7 B, C)$. In contrast, HA-NL1 $\Delta C$ mice failed to show a characteristic preference for social novelty, spending equal amounts of time with a familiar mouse and a novel mouse $(p>0.05$; Fig. $7 E, F)$. However, they still displayed a strong preference for social interaction relative to interaction with an object $(p<0.025$; Fig. $7 D)$. 

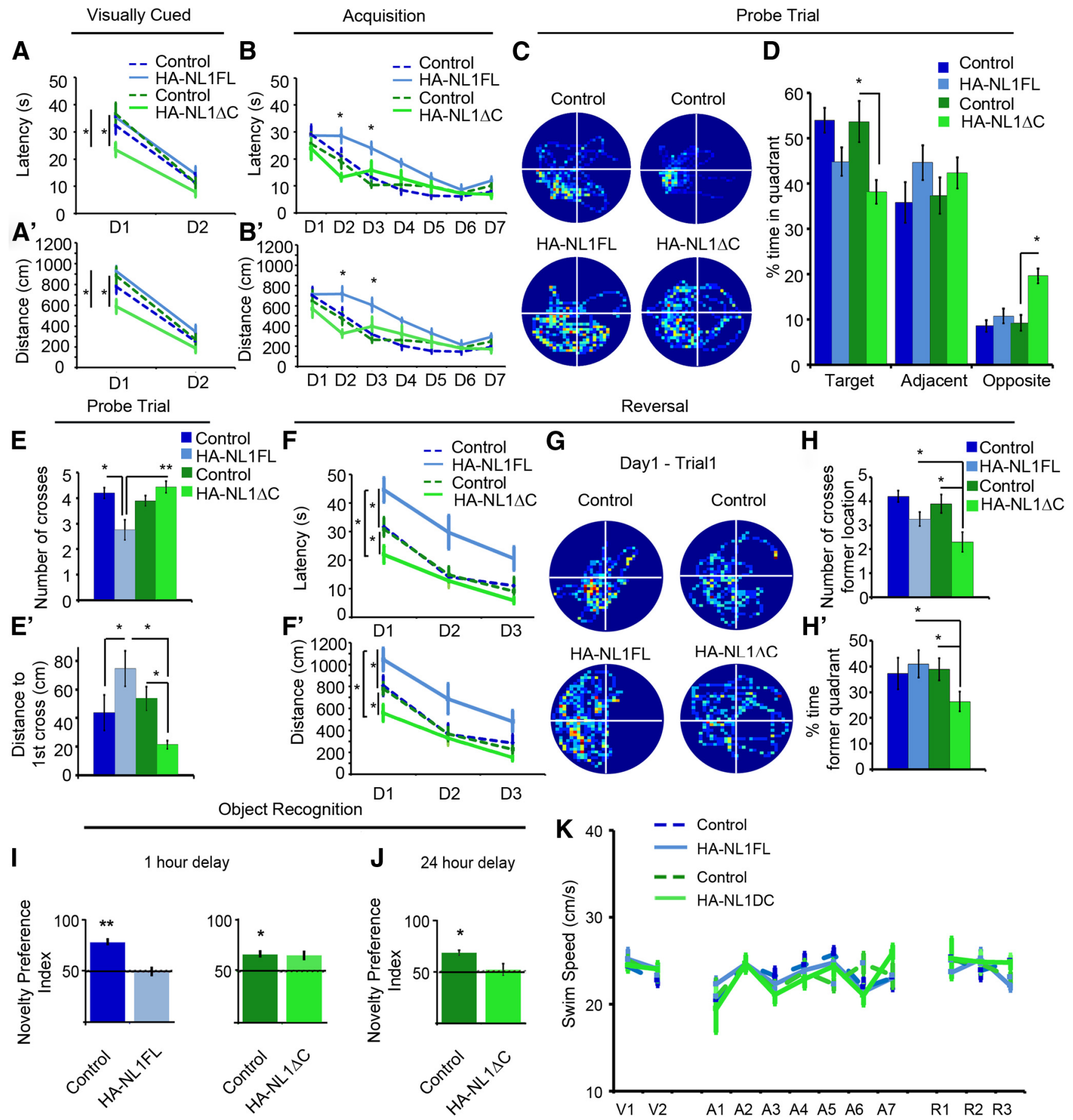

Figure 6. Manipulations of $\mathrm{NL} 1$ intracellular signaling distinctly alters performance in learning and memory behaviors. $A$, Mean latency in seconds (s) of transgenics (solid, light blue, and green lines) and their controls (dashed, dark blue, and green lines) during the visually cued training trials. Days of training labeled D1-D2. $\boldsymbol{A}^{\prime}$, Mean distance traveled before reaching the platform in the visually cued training trials. $\boldsymbol{B}$, Mean latency in seconds $(s)$ to find hidden platform during acquisition training showing significant differences in the performance of only the HA-NL1FL mice from controls. $\boldsymbol{B}^{\prime}$, Mean distance traveled before reaching the hidden platform during acquisition training showing significant differences in distances traveled to reach the platform. $C$, Representative paths traveled from each group of mice during a $60 \mathrm{~s}$ probe trial after acquisition training showing significant changes in searching behavior. All plots were oriented to align the target quadrant to the lower left for comparison purposes. $\boldsymbol{D}$, Significant differences in percentage time spent in either the target quadrant, quadrants adjacent to the target, or the opposite quadrant during the 60 s probe trial for the transgenics (light blue and green bars) versus each other and their controls (dark blue and green bars). $\boldsymbol{E}$, Significant differences in mean number of crosses of former platform location and $\left(\boldsymbol{E}^{\prime}\right)$ mean distance in centimeters to reach former target location during the $60 \mathrm{~s}$ probe trial following acquisition. $\boldsymbol{F}$, Significant differences in mean latency in seconds $(s)$ and $\left(\boldsymbol{F}^{\prime}\right)$ mean distance traveled $(\mathrm{cm})$ to reach new platform location in reversal training. Transgenics are labeled as solid, light blue, and green lines and their controls are dark blue and green, dashed lines. Days of training labeled D1-D3. G, Representative search paths on the fourth training trial of Day 1 of reversal training revealing distinct differences between transgenics and their controls. The former target location has been aligned to the lower left quadrant for comparison between groups, meaning the new location is in the upper right quadrant. $\boldsymbol{H}$, Mean number of crosses over former target location and $\left(\boldsymbol{H}^{\prime}\right)$ percentage time in former target quadrant during the fourth training trial of the first day between transgenics and controls serves as a measure of persistence in using old information after experiencing new conditions. $I$, Object recognition memory to assess short-term memory, $1 \mathrm{~h}$ delay between object exposure, and ( $\boldsymbol{(}$ ) long-term memory, $24 \mathrm{~h}$ delay, differences between HA-NL1FL mice (light blue bars) and HA-NL1 $\Delta$ C mice (light green bars). $\boldsymbol{K}$, Comparison of swim speeds in $\mathrm{cm} / \mathrm{s}$ between transgenic mice (solid, light blue, and green lines) and their controls (dashed, dark blue, and green lines) during distinct phases of water maze training. Days of visual training, V1-V2; days of acquisition training, A1-A7; and days of reversal training, R1-R3. All data shown are mean \pm SEM, significance determined with repeated-measures ANOVA with Tukey-Kramer HSD, posthoc, ${ }^{*} p<0.05, n=21$ littermate pairs (10-11 double positive transgenic in each group or 10-11 mixed single transgenic controls). 
HA-NL1FL

\section{A Social Preference B Social Novelty Preference \\ C Social Novelty Preference}
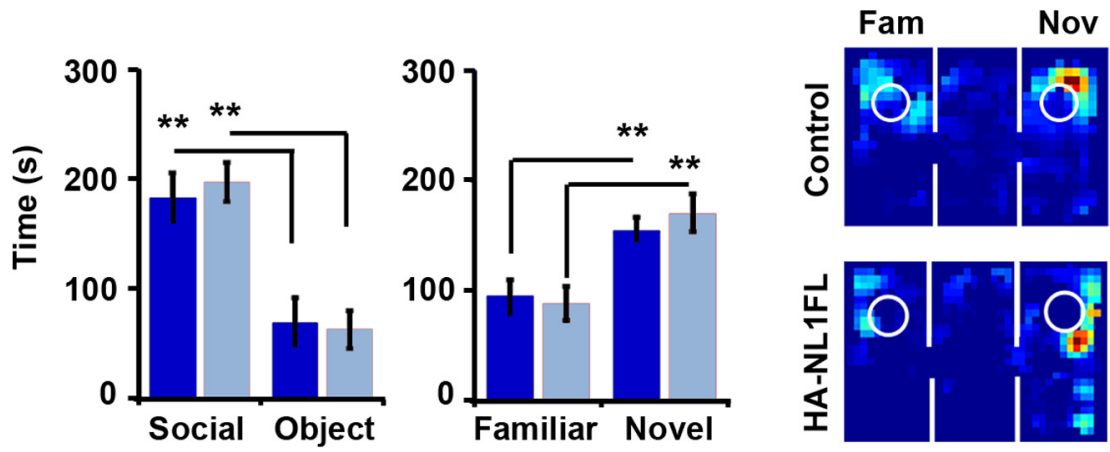

HA-NL1 $\Delta \mathrm{C}$
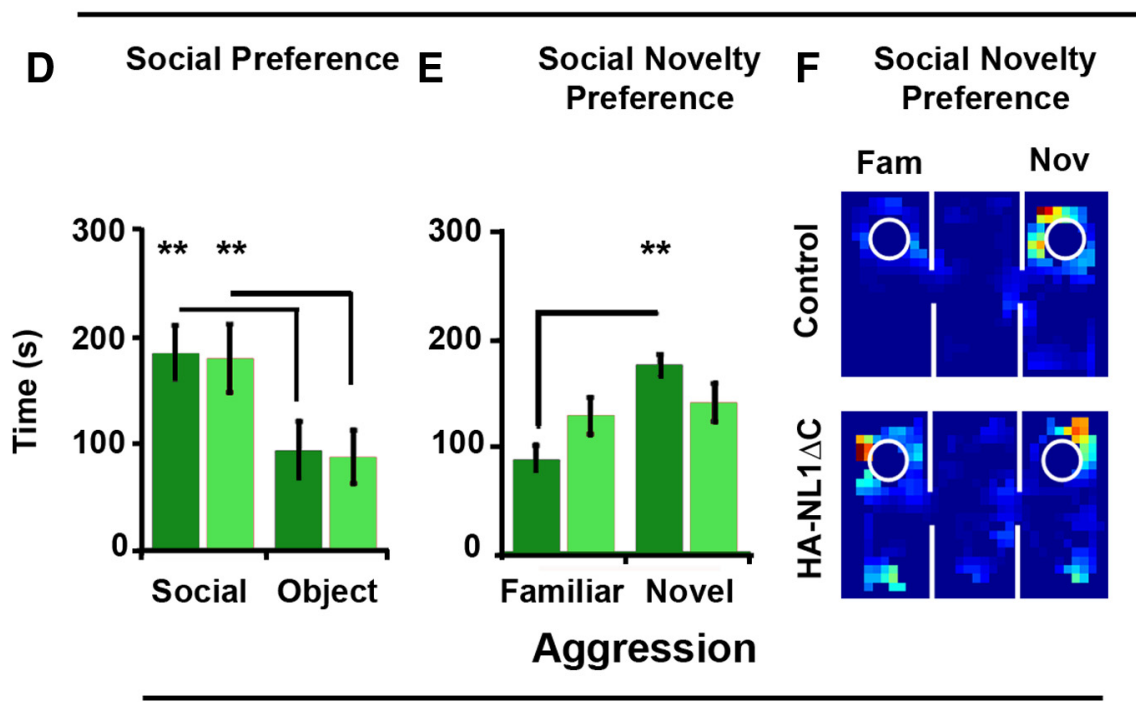

G
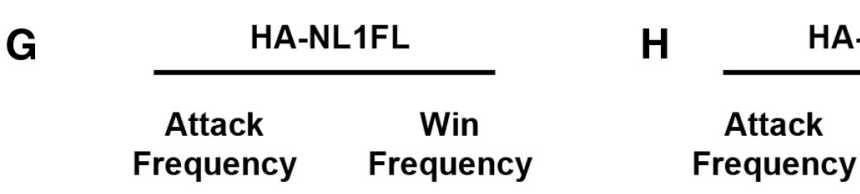

$\mathrm{HA}-\mathrm{NL} 1 \Delta \mathrm{C}$
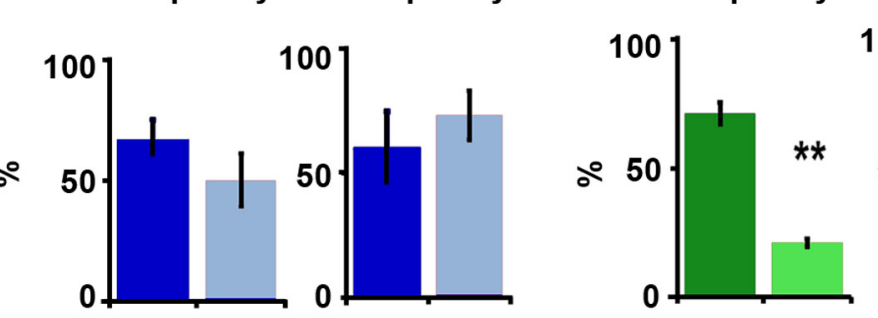

Figure 7. Manipulations of NL1 intracellular signaling affect social behavior. $\boldsymbol{A}$, Performance in the three-chambered social preference task. Mean time in seconds (s) spent in the chamber, with either a social partner (Social) or an object (Object), is depicted for both controls (dark blue bars) and HA-NL1FL mice (light blue bars) in the left graph. B, Mean time spent in a chamber with either a familiar social partner (Familiar) or a novel social partner (Novel) is depicted. C, Representative exploration paths during a choice to investigate a familiar or a novel social partner, control performance at top, and HA-NL1FL performance at bottom. D. Preference for social interaction over interaction with an object for control (dark green bars) and HA-NL1 $\Delta$ C mice (light green bars). $\boldsymbol{E}$, Significant differences in preference for familiar animals versus novel animals in controls (dark green bars) versus HA-NL1 $\Delta$ C mice (light green bars). $\boldsymbol{F}$, Representative exploration paths during a choice to investigate a familiar or a novel social partner, control performance at top, and HA-NL1 $\Delta$ C performance at bottom. G, Left, Attack frequency differences during the resident-intruder task after prolonged social isolation between controls (dark blue) and HA-NL1FL mice (light blue). Right, Win frequency during the dominance tube test is graphed to the right. $\boldsymbol{H}$, Left, Attack frequency differences during the resident-intruder task after prolonged social isolation between controls (dark green) and HA-NL1 $\Delta$ C mice (light green). Right, Win frequency differences between controls and the HA-NL1 $\Delta$ C mice. All data shown are mean \pm SEM, significance was determined with repeated-measures ANOVA, with Tukey-Kramer HSD post hoc, ${ }^{*} p<0.05,{ }^{* *} p<0.01, n=21$ pairs (10-11 double positive transgenic in each group or 10-11 mixed single transgenic controls).
The lack of preference for a novel partner in the HA-NL1 $\Delta$ C mice is unlikely to be due to the previously described differences in learning and memory, as similar tests for novel objects revealed a preference for novel objects with a delay between exposures of up to an hour. In these tests for social novelty, the delay between different phases of testing is only $15 \mathrm{~min}$. Therefore, we observed a selective change in social novelty preference and not a change in preference for novelty.

We also assessed aggression and dominance behavior in male mice using both the resident-intruder task and dominance tube test (Messeri et al., 1975; Duncan et al., 2004; Moy et al., 2004). In the resident-intruder task, we saw no significant difference between the HA-NL1FL mice and controls in their interaction during this task (Fig. $7 G$, left). However, we found that the HA-NL1 $\Delta$ C mice were less likely to initiate an attack than their controls $(16.7 \pm 1.1 \%$ vs $56.7 \pm 3.3 \%, p<$ $0.025, n=9$ pairs; Fig. $7 H$, left). We saw no other significant effects in other forms of social interactions during this test, including dominant mounting behaviors (data not shown). The dominance tube test can also be used to confirm differences in dominance as it pits two mice against each other in a confined tube in which a more dominant male would force the less dominant to retreat. This test assesses more subtle levels of dominance in social interaction that may be present, but may not result in more aggressive acts such as mounting or fighting. We again found no difference in this behavioral test between the HA-NL1FL mice and their controls (Fig. $7 G$, right). Consistent with the observed differences in likelihood to attack, the HA$\mathrm{NL} 1 \Delta \mathrm{C}$ mice were also more likely to be submissive when pitted against group housed control mice in the dominance tube test (Fig. $7 H$, right). Overall, these results suggested that expression of HANL1 $\Delta C$ resulted in a decrease in overt acts of aggression in addition to the lack of preference for social novelty, while overexpression of HA-NL1FL failed to yield significant differences in social interaction in our assays.

Overexpression of NL1FL is not necessary to maintain changes in synaptic maturation nor behavior, but can initiate changes in behavior in the adult

It is currently an open question as to whether NL1 levels at the synapse are required to maintain synapses in a mature state or whether they only initiate the cas- 
A

off Dox

(HA-NL1FL Overexpressed)

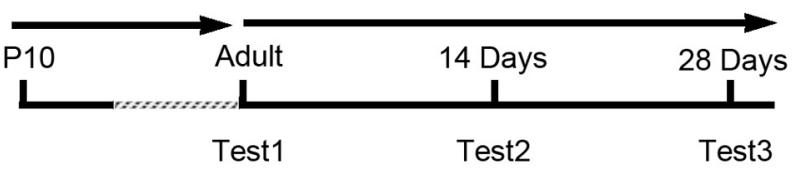

B

on Dox

(Overexpression Off)

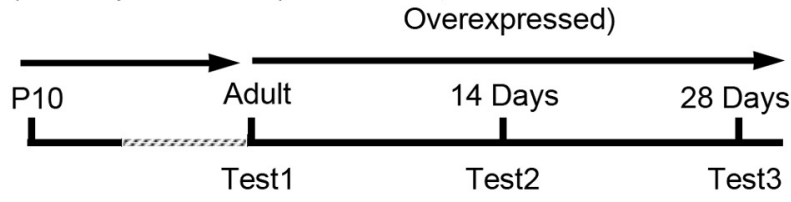

Early OE

on Dox

(Overexpression Off)

ate $\mathrm{OE}$

off Dox

D Early OE - spine head area $\left(\mu \mathrm{m}^{2}\right)$
A'

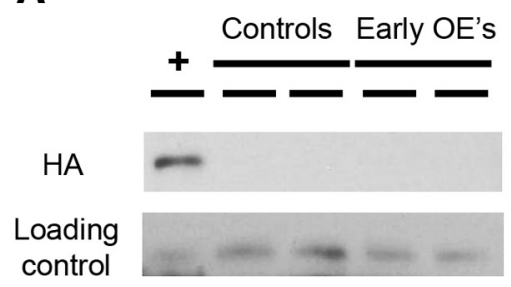

B'

HA

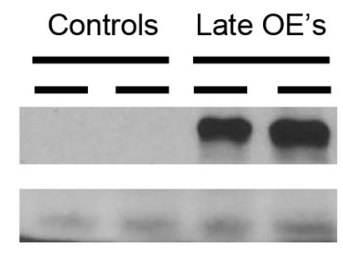

E Late OE - spine head area $\left(\mu \mathrm{m}^{2}\right)$
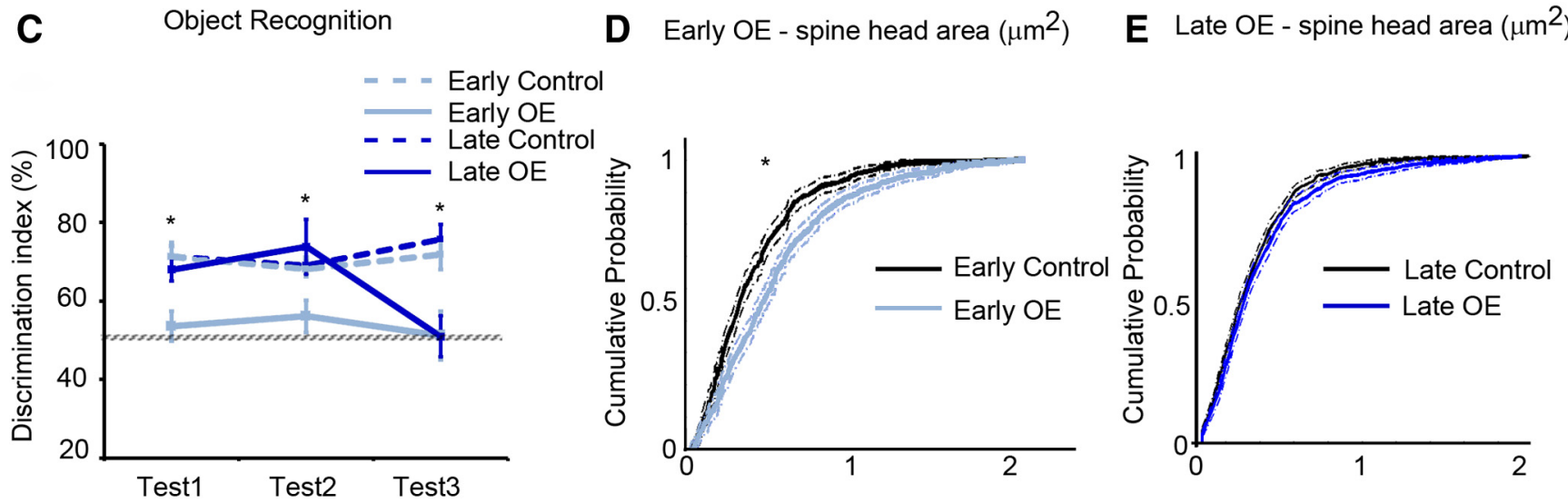

Figure 8. Overexpression of NL1FL is not required to maintain changes in synaptic maturation nor behavior, and can initiate behavioral changes in the adult. $\boldsymbol{A}$, Summary of the experimental procedure to induce overexpression of HA-NL1FL only during development in adolescence, the Early OEs. Behavioral testing occurred first at the time when HA-NL1FL was still overexpressed (Test1), then 2 weeks after transgene expression was inhibited (Test2), and then again after 4 weeks of transgene inhibition (Test3). $\boldsymbol{A}^{\prime}$, Western blots performed on forebrain homogenate of mice upon completion of behavioral testing to assess presence of transgene, + is cell lysate with HA-NL1FL present to confirm HA immunolabeling. $\boldsymbol{B}$, Summary of the experimental procedure to induce HA-NL1FL overexpression only in the adult, leaving critical developmental periods unperturbed, the Late OEs. Initial behavior testing in these animals started just before HA-NL1 overexpression was induced in the Late 0Es, (Test1), 2 weeks after transgene expression induction (Test2) and 4 weeks after induction (Test3). $\boldsymbol{B}^{\prime}$, Western blot confirmation of HA-NL1FL overexpression in Late 0Es. All experimental groups were compared with cohoused single positive littermates simultaneously on the same Dox diet regime. $\boldsymbol{C}$, Performance in the object recognition task as measured by the novel object discrimination index (\%) at the designated testing periods. Transgenic performances are shown in light and dark solid lines and control performances are depicted by light and dark dashed lines. All data shown are mean \pm SEM, and significance determined by repeated-measures ANOVA. D. Cumulative distributions with associated confidence intervals for spine head size of the synaptic population within the SLM from the Early OEs (light blue) and their controls (black), ${ }^{*} p<0.05$, Kolmogorov-Smirnov test. E, Cumulative distributions with associated confidence intervals for spine head size in the Late OEs (dark blue) and their controls (black), $p>0.05$, Kolmogorov-Smirnov test, $n \geq 36$ dendritic spine segments from three to four animals in each group.

cade of events that bring about important changes at the synapse. Addressing this question would advance our understanding of when NL1 is most able to influence synaptic state and behavior. To examine this question, we characterized the consequences of transient overexpression of full-length NL1 during development on adult synaptic state and behavior. In our transgenic mice, the capability to overexpress NL1 was regulated by the tTA genetic system, affording temporal control of transgene expression. We examined the synaptic and behavioral consequences when NL1FL was conditionally overexpressed once adulthood had already been reached. We previously demonstrated that constitutive overexpression of NL1 (from P10 to time of testing) inhibits learning and memory behavior in adult mice with the object recognition task (Fig. 6I,J). Mice in which HA-NL1FL was overexpressed from P10 through 2 months of age, the Early OE mice (Fig. 8A), also displayed learning and recall deficits in the object recognition task when tested up to a month beyond returning NL1 expression to wild-type levels (Test 3: $51.28 \pm 9.21 \%$ vs chance performance, $p>0.05$; Fig. $8 C$ ). Western blots confirmed the absence of transgene expression after 1 week of Dox administration and at the time of behavioral testing (Fig. $8 A^{\prime}$; see Materials and Methods). DiI labeling and characterization of spine morphology revealed that the average spine head area of the Early OEs was also significantly larger than those from littermate single positive controls $(p<0.001$, Kolmogorov-Smirnov test; Fig. $8 D)$. There were no significant differences in the number of spines per unit of dendrite length in the SLM of these mice ( $p>$ $0.05)$. These results suggest that NL1FL overexpression-induced maturation of synaptic structures and memory impairment was stable even when NL1 overexpression was removed.

We compared these results to those of mice where overexpression of full-length NL1 was inhibited until adulthood (Late OE). We confirmed that overexpression of HA-NL1FL was driven to levels similar to constitutive animals within $10 \mathrm{~d}$ of induction in the Late OE mice (Fig. 8B; see Materials and Methods). Remarkably, after only $28 \mathrm{~d}$ of transgene induction, we detected an effect 

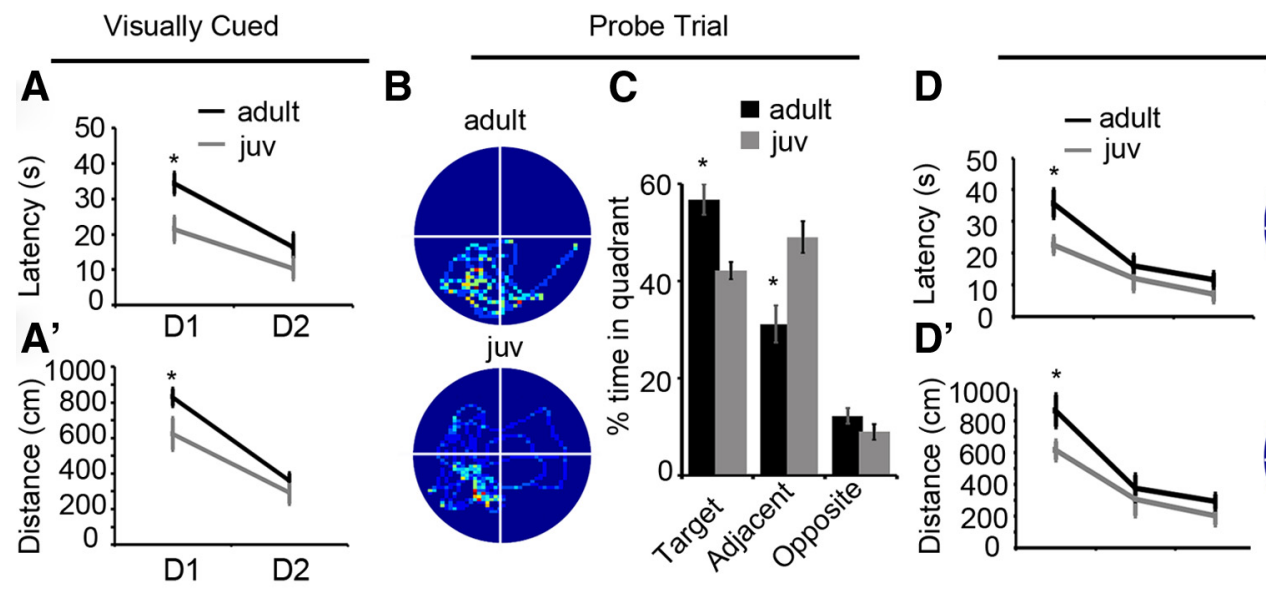

Reversal
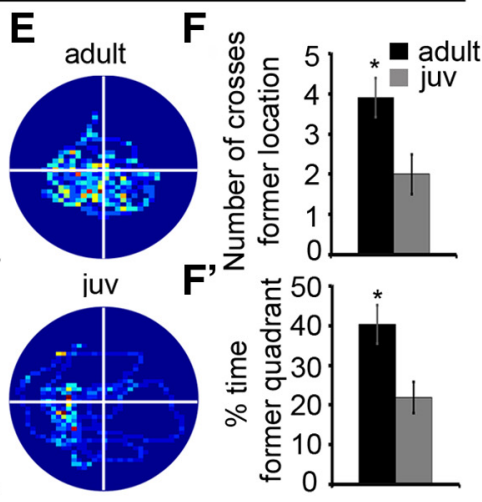

\section{G Social Preference H Social Novelty I Social Novelty Preference Preference}
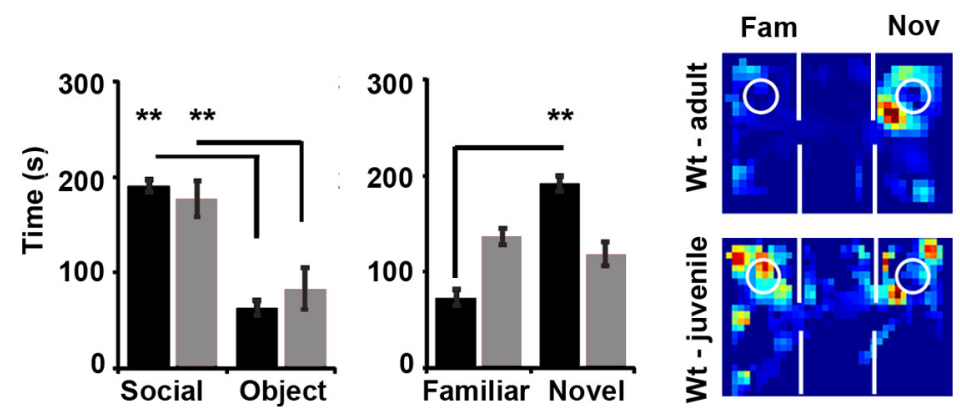

Figure 9. Learning, memory. and social behavior of wild-type juvenile mice. Water maze performance of 1-month-old wild-type Bl6 juvenile males (gray lines and bars) relative to their strain and sex matched adult controls (black lines and bars) for measures that we found significantly different in the HA-NL1 $\Delta$ C mice: mean latency $(\boldsymbol{A})$ and distance $\left(\boldsymbol{A}^{\prime}\right)$ of visually cued training, representative paths of probe trial $(\boldsymbol{B})$, and percentage time spent in target quadrant $(\boldsymbol{C})$, mean latency $(\boldsymbol{D})$, and distance $\left(\boldsymbol{D}^{\prime}\right)$ during reversal training, representative paths, and number of crosses of former location $(\boldsymbol{F})$ and percentage of time spent in former target quadrant $\left(\boldsymbol{F}^{\prime}\right)$. All target quadrants have been aligned to place the target in the lower left quadrant. $\mathbf{G}-\boldsymbol{I}$, Wild-type adult social preferences (black) versus wild-type juvenile social preferences (gray). All data shown are mean \pm SEM, significance determined with repeated-measures ANOVA with Tukey-Kramer HSD, post hoc, ${ }^{*} p<0.05, n=$ 10 pairs (10 juveniles and 10 adults).

on behavioral performance $(p<0.01$; Fig. $8 C)$. However, at this time point we did not detect a significant change in spine density, nor spine head area in the Late OE mice $(p>0.05 ;$ Fig. $8 E)$. This suggests that NL1 is capable of initiating changes to synaptic function that impact behavior in the adult; but those changes occur without measurable changes in synaptic morphology. Together these data support the idea that overexpression of NL1 is not necessary to maintain decreased learning ability and enlarged synapses, but that the effects incurred earlier in development translate to lifelong changes in synaptic structure and behavior. Surprisingly, NL1 is sufficient to alter learning behavior and presumably synaptic function in the adult, without measureable changes in spine head size.

Flexibility in learning and memory tasks and lack of social preference are distinctly different in juveniles during normal development

Given that we had evidence that NL1 overexpression impacted processes in the juvenile phase of development, we sought to establish whether the changes in behavior that we observed in our transgenics could relate to how these behaviors normally matured. Therefore, we characterized wild-type juvenile performance in C57BL/6J mice relative to adult mice in the Morris water maze and social approach tasks. To our knowledge, this had not previously been characterized, and this information would help establish whether our genetic perturbations, and how they affected synaptic development, had any relevance to normal behavioral development in addition to pathological states. Twentyeight-day-old mice were the youngest juveniles that were able to perform the water maze task without a significant difference in thigmotaxic behavior and swim speed relative to the adults (data not shown). We found a significant decrease in the latency and distance to reach the visually cued platform on the first day of visually cued training for the juveniles relative to adults (21.37 \pm $3.60 \mathrm{~s}$ vs $34.26 \pm 2.69 \mathrm{~s}, p<0.025$, post hoc, main effect of age on latency: $F_{(1,22)}=8.2, p<0.01$, main effect of day: $F_{(1,22)}=18.92$, $p<0.001$; Fig. $\left.9 A, A^{\prime}\right)$. While it is difficult to know how improved performance on this phase of the task relates to learning and memory behaviors per se, it is nonetheless an interesting phenotype that appears to change over normal development.

We next observed key differences in behavior between adults and 28-d-old juveniles during probe trial performance and reversal training. Juveniles and adults both spent more time in the target quadrant than would be expected by chance, but significantly differed in their degree of preference $(43.9 \pm 2.9 \%$ vs $54.9 \pm 3.3 \%$, respectively, $p<0.025$; Fig. $9 B, C$ ). However, there were no differences between the juveniles and the adults in the number of crosses made over the former platform location during the $60 \mathrm{~s}$ trial $(4.3 \pm 0.7$ vs $5.0 \pm 0.6, p>0.05)$, nor was the distance to first cross the former target location different $(48.21 \pm 4.32 \mathrm{~cm}$ vs $55.21 \pm 8.1 \mathrm{~cm}, p>0.05)$. Thus, juveniles tended to occupy a greater area on the pool when searching dur- 
Table 3. Overall phenotypic differences between HA-NL1FL and HA-NL1 $\Delta C$ mice

\begin{tabular}{lll}
\hline Assay & HA-NL1FL & HA-NL1 $\Delta C$ \\
\hline Synapse number & No $\Delta$ & $\uparrow$ Spines and PSD-95 cluster density \\
Synapse size & $\uparrow$ Spine head size & No $\Delta$ \\
& Synapsinl area & \\
Protein levels & $\uparrow$ Shank & $\uparrow$ SAP102 $\downarrow$ Sap97 \\
& PICK1 & PSD-95 \\
& Sap97 & NR2B \\
Basal synaptic transmission & $\uparrow$ NR2A & \\
& $\tau$ NMAR/AMPAR & No $\Delta$ \\
PP-LTP & No $\Delta$ & \\
Water maze & $\downarrow$ Reversal learning & No $\Delta$ \\
Social behavior & No $\Delta$ & $\downarrow$ Reversal learning \\
& & $\downarrow$ Aggression \\
& & Social novelty \\
& & Preference
\end{tabular}

Left column summarizes effects of interest compared between our mice. Middle and right columns summarize whether a change in the phenotype is measured, and arrows delineate sign of change relative to controls.

ing the probe trial. Juveniles also performed significantly different from adults during reversal training (main effect of age on latency: $F_{(1,36)}=8.85, p<0.01$, main effect of day: $F_{(2,36)}=21.82$, $p<0.001$, and no age $\times$ day interaction, $p>0.05)$. Twentyeight-day-old mice located the new platform location significantly faster than their adult counterparts $(22.45 \pm 2.66 \mathrm{~s}$ vs $35.57 \pm 4.42 \mathrm{~s}, p<0.05$; Fig. $\left.9 D, D^{\prime}\right)$, made fewer crosses of the former target location $(2.00 \pm 0.51$ vs $3.90 \pm 0.5, p<0.01$; Fig. $9 F)$ and had lower dwell times in the former target quadrant $\left(21.87 \pm 4.39 \%\right.$ vs $40.26 \pm 5.08 \%, p<0.01$; Fig. $\left.9 F^{\prime}\right)$. Overall, these results suggest that wild-type juvenile mice exhibit more flexibility in learning the water maze task and suggest that flexibility is a behavioral trait that undergoes developmental transitions.

Finally, we found that 28-d-old juvenile mice of the same background strain (C57BL/6J) lacked a preference for social novelty without lacking preference for social interaction as compared with adult mice (social vs object preference in juveniles: $p<0.01$, familiar vs novel partner: $p>0.05$; Fig. $9 G-I$ ). This suggests that complex features of social interaction also undergo important developmental transitions and it would be interesting to further explore how other developmental states and social contexts modulate this behavioral tendency.

\section{Discussion}

In this study, we explored the molecular, cellular, and behavioral phenotypes associated with regionally and temporally restricted NL1 overexpression. We contrasted that manipulation to one in which we overexpressed NL1 missing the last 55 aa within the $\mathrm{C}$ terminus (Table 3 ). This comparison was intended to provide insight into the molecular mechanisms by which NL1 affects synaptic structure and behavior relevant to both the normal development of mice, as well pathological states observed in humans with neurodevelopmental disorders. We present evidence that the NL1 C terminus is necessary for the induction of key features of synaptic maturation when NL1 is overexpressed in vivo. Moreover, we show for the first time that such molecular and cellular changes correlated with changes in flexibility in learning and memory, and, social preference. Importantly, we also provide novel evidence that these same behavioral traits change over normal development in mice. Thus, we link our specific NL1 manipulations to behaviors that are distinct at juvenile and mature phases of development. Finally, as flexibility in learning and memory and social preference are traits affected in ASD, we believe that our results have significant implications for our understanding of how NL1 relates to the etiology of pervasive neurodevelopmental disorders in addition to its roles during normal development.

\section{Specific molecular targets are affected by our manipulations of NL1}

At the cellular level, our studies found important differences between HA-NL1FL overexpression and that of HA-NL1 $\Delta \mathrm{C}$. We discovered that HA-NL1FL overexpression resulted in a bias toward synapses with larger spine heads containing more Shanks, PICK1, SAP97, NR2A, and Synapsin1; these features are associated with mature synaptic structures (Fig. $2 A, C, 3 A, E$ ). Recordings in CA1 showed that NL1FL overexpression drove an increase in the NMDAR to AMPAR ratio (Fig. 4A; Chubykin et al., 2007), presumably revealing more NMDARs in each large spine head. These results are consistent with previous studies of NL1FL overexpression in vivo (Dahlhaus et al., 2010) and suggest that overexpression of NL1FL leads to a reliable increase in specific molecular and structural features associated with mature synapses, in addition to a strong positive effect on NMDAR recruitment and function in vivo. The increase in NMDA/AMPA ratio was not associated with changes in the magnitude of NMDARdependent TBS LTP in animals assayed at the ages where behavior is observed. This is in contrast to the deficits observed in high-frequency stimulation LTP measured in mice with ubiquitous NL1 overexpression (Dahlhaus et al., 2010). This specific discrepancy can be explained by the significant differences in expression pattern between the two animal models and our choice to employ a TBS protocol (Larson et al., 1986; Larson and Lynch, 1988; Capocchi et al., 1992). Although we did not find a deficit in TBS LTP induction at the perforant path, the difference in NMDAR to AMPAR ratio and the longer decay constant in the FL overexpressing mice might be expected to alter network dynamics and potentially alter information processing or encoding (Daw et al., 1993; Schiller and Schiller, 2001). Our evidence will therefore direct future investigations toward understanding how alternative forms of plasticity and/or changes in basal NMDARmediated synaptic transmission in the adult are sufficient to account for the behavioral phenotypes described here. Additionally, we find evidence that NL1 shapes neural circuit function later in life via processes occurring earlier in development (Fig. 8). Therefore, future investigations of how NL1 function during the development of the hippocampus specifically affects later plasticity processes will provide additional understanding of how NL1 mechanistically supports changes in behavior.

In contrast, overexpression of HA-NL1 $\Delta \mathrm{C}$ generated a distinct set of synaptic consequences that were still related to a similar network of developmentally relevant postsynaptic scaffolding molecules and glutamate receptors. In the NL1 $\Delta \mathrm{C}$ mice, we observed an increase in the number of spines, decreased levels of Synapsin 1 and SAP97, and increased levels of SAP102 and NR2B (Figs. 2B, $D, 3 B, D$ ). Moreover, overexpression of this form of NL1 did not result in a significant change in NMDAR to AMPAR ratio (Fig. $4 A$ ). Therefore HA-NL1 $\Delta \mathrm{C}$ did not induce identical changes in molecular and cellular synaptic phenotypes. Since there were no significant differences in overexpression levels, or localization characteristics between HA-NL1FL and HA- NL1 $\Delta \mathrm{C}$ mice (Fig. 1), these results provide evidence that the induction of an abundance of mature synaptic features by the overexpression of HA-NL1FL required the last 55 aa of the molecule. This is one of the first accounts that this region of NL1 is required for these specific activities at the synapse. 
Surprisingly, however, overexpression of NL1 $\Delta \mathrm{C}$ positively affected synapse number and at least two developmentally relevant synaptic molecules, SAP102 and NR2B (Vicini et al., 1998; Sans et al., 2003; van Zundert et al., 2004; Washbourne et al., 2004; Petralia et al., 2005; Zheng et al., 2011). While we may not completely rule out nonphysiological gain of function effects resulting from overexpressing HA-NL1 $\Delta \mathrm{C}$, this manipulation does alter synaptic structure and biochemical composition in a manner predicted based on the molecular pathways that NL1 is known to specifically affect in vivo and in vitro. In particular, previous biochemical and cellular studies suggest that manipulations of NL would differentially affect SAP102 levels, which could in turn influence NR2B localization to synaptic structures, relative to other synaptogenic molecules (Meyer et al., 2004). Therefore, the molecular effects of HA-NL1 $\Delta \mathrm{C}$ overexpression are specific in the sense that they do not ubiquitously affect all postsynaptic excitatory molecules, and are restricted to the subset of effectors and receptors predicted to interact with NLs through the course of normal synaptic development (Chubykin et al., 2007; Blundell et al., 2010; Dahlhaus and El-Husseini, 2010; Dahlhaus et al., 2010; Schapitz et al., 2010). Finally, at least three other recent studies have argued that under specific conditions where endogenous NL1 is removed, extracellular portions of the protein, and a novel domain within the intracellular tail region also perform important roles in NMDAR recruitment and synapse formation (Shipman et al., 2011; Shipman and Nicoll, 2012; Budreck et al., 2013). This does not necessarily negate our conclusion that the last 55 aa also serve important roles at the synapse, especially in the context of an otherwise unaltered mouse. At least one region within the last 55 aa of NL1 is necessary to induce the overabundance of mature synaptic features when NL1FL is overexpressed because such structures cannot be induced via NL1 $\Delta \mathrm{C}$ overexpression in our studies (Table 1). Therefore, our study uniquely adds to this growing body of work as we provide the first evidence that abnormal levels of different regions of this protein differentially impact developmentally relevant aspects of behavior in mice.

Notably, we now show important ways that NL1FL and NL1 $\Delta C$ overexpression differs from that of SynCAM1 (Robbins et al., 2010). SynCAM1 is a distinct synaptogenic CAM that modulates distinct downstream targets (Meyer et al., 2004). First, targeted NL1FL overexpression did not strongly increase the number of synapses in the adult while SynCAM1 overexpression does. Second, NL1 alters the NMDAR/AMPAR ratio, changing basal synaptic transmission. SynCAM1 overexpression does not. Third, NL1FL overexpression appears to alter learning and memory behavior to a lesser extent than SynCAM1. SynCAM1 overexpressing adult mice are unable to learn to find the hidden platform efficiently. Fourth, and possibly most intriguingly, we find that the consequences of transient NL1 overexpression in the younger animal persist into adulthood in mice, while SynCAM1 must be maintained at synapses to affect synapse number. Importantly, Robbins et al., (2010) used the same CaMKII-tTA expression system. Therefore, this novel data support the idea that the overexpression of these molecules distinctly perturbs synapse number, function, and maturation, and are relevant at different developmental phases.

Distinct manipulations of NL1 differentially perturb behavior If we consider behavioral changes as a whole, then there are clear quantitative differences in how the HA-NL1FL and HA-NL1 $\Delta \mathrm{C}$ perform in learning, memory, and social behaviors. We first consider differences in performance during the water maze task. The
HA-NL1FL mice show clear deficits in initially reaching the hidden platform in the most efficient manner relative to all other groups, and trend toward less time in the target quadrant during the probe trial than control groups (Fig. 6B,D). Careful consideration of simultaneously measured parameters during the probe trial additionally suggests that HA-NL1FL mice significantly differ from HA-NL1 $\Delta$ C mice. Of particular note, HA-NL1 $\Delta$ C spend significantly more time in the opposite quadrant over the probe trial, while the HA-NL1FL mice distribute their searching behavior between the target and directly adjacent quadrants (Fig. 6D). Importantly, HA-NL1 $\Delta \mathrm{C}$-expressing mice showed a significantly higher number of crosses and a shorter distance to first cross the former platform location. This is quite the opposite of the behavior observed in the HA-NL1FL animals. These data support that HA-NL1 $\Delta$ C mice did not display learning and memory deficits per se; rather, they displayed decreased perseverance in searching the target quadrant during the probe trial. This argues that differences between these groups of mice relate to systems that implement flexibility of search strategy as opposed to pure memory per se (Fig. 6C). The differences in the reversal data (Fig. $6 F-H$ ), as well as the fact that the HA-NL1 $\Delta \mathrm{C}$ mice are quicker to reach a visually cued platform without significant changes in their basic locomotor behavior (Fig. $6 A, A^{\prime}, K$ ), all point to robust, yet differential, changes in flexibility between the two lines of mice. Indeed, other research groups have similarly argued for the need to consider that differences in persistent searching behavior during the reversal component of the water maze task could point to changes in behavioral flexibility in using stored information (Brown and Kraemer, 1997; Janus, 2004; Vorhees and Williams, 2006; Arque et al., 2008; Dolleman-van der Weel et al., 2009; McKirdy et al., 2009; Izquierdo and Jentsch, 2012). Because of the significant quantitative differences we observed in behavior in the water maze between the two groups, we conclude that overexpressing HA-NL1FL distinctly impacted learning, memory, and flexibility in behavior as compared with when HA-NL1 $\Delta$ C was overexpressed to similar levels.

Finally, social interaction behaviors are also affected differentially between the groups of mice. We are unable to detect significant changes in social approach or aggression in mice overexpressing HA-NL1FL (Fig. 7A, G). This dissociates our observed molecular and cellular changes within targeted regions from significant alterations to these aspects of this behavioral domain. However, other work suggests that more complicated aspects of social interaction such as normal vocal behavior could still be impacted via manipulations to downstream targets such as Shank3 that we may have modulated by HA-NL1FL overexpression (Bozdagi et al., 2010). Interestingly, overexpression of HA-NL1 $\Delta \mathrm{C}$ significantly affected both aggression and social preference (Fig. $7 D-F, H$ ). Together, these behavioral data argue that important behavioral differences exist between our two transgenic lines.

\section{These manipulations model synaptic changes and behaviors relevant to neurodevelopmental disease}

It is still unclear how differences in synaptic development may alter learning, memory and social behaviors that are relevant to those affected in human neurodevelopmental disorders. However, previous investigations of NL family function in vivo suggested links between the cellular processes governed by NLs and these complex behavioral domains (Hines et al., 2008; Jamain et al., 2008; Blundell et al., 2010; Dahlhaus and El-Husseini, 2010). Additional work shows that in vivo manipulations of the scaffolding molecules that we show are positively regulated by NL1 overexpression yields pathologically relevant changes in learning, 
memory, and social behavior in mice, changes reminiscent of developmental disorders (Kim and Sheng, 2004; Hung et al., 2008; Bozdagi et al., 2010; Bangash et al., 2011; Peça et al., 2011; Poglia et al., 2011). Thus, forced recruitment of such scaffolding molecules by NL1FL overexpression are likely to have been related to the observed behavioral changes described here.

There is an association between ASDs and incidence of copy number variation $(\mathrm{CNV})$ of the postsynaptic molecules we find modulated here (Glessner et al., 2009). Additionally, mutations in NL1's 3' region have also been implicated in ASD (Ylisaukkooja et al., 2005). The $3^{\prime}$ mutations are found in introns close to the end of the coding sequence corresponding to the intracellular region. Furthermore, targeted HA-NL1FL overexpression in our studies led to decreases in flexibility in learning and memory behaviors. This contrasted a surprising enhancement in flexibility and social preference in HA-NL $1 \Delta$ C overexpressing mice. Indeed, the behavioral data gathered on HA-NL1 $\Delta \mathrm{C}$ mice bore remarkable similarities to those traits exhibited by typically developing juvenile mice across multiple behavioral domains relevant to neurodevelopmental disorders (Fig. 9). This specific data argue that it will be important in future studies to consider how the changes in synaptic state induced by the overexpression of HA-NL1 $\Delta \mathrm{C}$ led to juvenile-like tendencies in these aspects of behavior. The data considered as a whole, in conjunction with known mutations associated with ASDs, speak to the relevance of both the NL1FL and NL1 $\Delta$ C overexpressing mice as animal models of the biological etiology of changes in flexibility associated with neurodevelopmental disorders.

Importantly for future considerations of potential gene therapies to overcome genetic forms of ASD, our results suggest that NL1 overexpression (or CNV), resulting in learning and memory deficits, cannot be reversed by knockdown in the adult (Fig. 8C). This implies that there may be an early critical period for RNAibased interventions in these cases. In contrast, the ability of exogenous NL1 to drive learning and memory deficits, implying the induction of synaptic changes in the adult (Fig. 8C), suggests that null mutations in NL1 may be overcome by viral-based expression of a NL1 transgene even in the mature nervous system, as has been shown for NL3 (Baudouin et al., 2012). These observations may pave the way to identifying critical periods of gene therapybased interventions for NL1-dependent and other forms of nonsyndromic ASD.

Together, this set of studies validates the role of NL1-mediated processes in the maturation of complex behaviors, and hones in on the molecular pathways that may specifically regulate flexibility in such behaviors. Furthermore, our results validate the idea that NL1 intracellular signaling domains regulate late stages of synaptic maturation in vivo, and provide the first evidence, that artificially manipulating the relative proportion of glutamatergic synapses in one state versus another in vivo, within specific neural systems, alters behavioral traits that change as a function of development.

\section{References}

Ahmed MS, Siegelbaum SA (2009) Recruitment of N-Type Ca(2+) channels during LTP enhances low release efficacy of hippocampal CA1 perforant path synapses. Neuron 63:372-385. CrossRef Medline

Amaral DG, Schumann CM, Nordahl CW (2008) Neuroanatomy of autism. Trends Neurosci 31:137-145. CrossRef Medline

Arque G, Fotaki V, Fernández D, Martínez de Lagrán M, Arbonés ML, Dierssen M (2008) Impaired spatial learning strategies and novel object recognition in mice haploinsufficient for the dual specificity tyrosineregulated kinase-1A (Dyrk1A). PLoS One 3:e2575. CrossRef Medline

Bangash MA, Park JM, Melnikova T, Wang D, Jeon SK, Lee D, Syeda S, Kim
J, Kouser M, Schwartz J, Cui Y, Zhao X, Speed HE, Kee SE, Tu JC, Hu JH, Petralia RS, Linden DJ, Powell CM, Savonenko A, et al. (2011) Enhanced polyubiquitination of Shank3 and NMDA receptor in a mouse model of autism. Cell 145:758-772. CrossRef Medline

Barrow SL, Constable JR, Clark E, El-Sabeawy F, McAllister AK, Washbourne P (2009) Neuroligin 1: a cell adhesion molecule that recruits PSD-95 and NMDA receptors by distinct mechanisms during synaptogenesis. Neural Dev 4:17. CrossRef Medline

Baudouin SJ, Gaudias J, Gerharz S, Hatstatt L, Zhou K, Punnakkal P, Tanaka KF, Spooren W, Hen R, De Zeeuw CI, Vogt K, Scheiffele P (2012) Shared synaptic pathophysiology in syndromic and nonsyndromic rodent models of autism. Science 338:128-132. CrossRef Medline

Bevins RA, Besheer J (2006) Object recognition in rats and mice: a one-trial non-matching-to-sample learning task to study 'recognition memory,' Nat Protoc 1:1306-1311. CrossRef

Blundell J, Blaiss CA, Etherton MR, Espinosa F, Tabuchi K, Walz C, Bolliger MF, Südhof TC, Powell CM (2010) Neuroligin-1 deletion results in impaired spatial memory and increased repetitive behavior. J Neurosci 30: 2115-2129. CrossRef Medline

Bourgeron T (2009) A synaptic trek to autism. Curr Opin Neurobiol 19: 231-234. CrossRef Medline

Bozdagi O, Sakurai T, Papapetrou D, Wang X, Dickstein DL, Takahashi N, Kajiwara Y, Yang M, Katz AM, Scattoni ML, Harris MJ, Saxena R, Silverman JL, Crawley JN, Zhou Q, Hof PR, Buxbaum JD (2010) Haploinsufficiency of the autism-associated Shank3 gene leads to deficits in synaptic function, social interaction, and social communication. Mol Autism 1:15. CrossRef Medline

Brown RW, Kraemer PJ (1997) Ontogenetic differences in retention of spatial learning tested with the Morris water maze. Dev Psychobiol 30:329_ 341. CrossRef Medline

Budreck EC, Kwon OB, Jung JH, Baudouin S, Thommen A, Kim HS, Fukazawa Y, Harada H, Tabuchi K, Shigemoto R, Scheiffele P, Kim JH (2013) Neuroligin-1 controls synaptic abundance of NMDA-type glutamate receptors through extracellular coupling. Proc Natl Acad Sci U S A 110: 725-730. CrossRef Medline

Burton SD, Johnson JW, Zeringue HC, Meriney SD (2012) Distinct roles of neuroligin-1 and SynCAM1 in synapse formation and function in primary hippocampal neuronal cultures. Neuroscience 215:1-16. CrossRef Medline

Capocchi G, Zampolini M, Larson J (1992) Theta burst stimulation is optimal for induction of LTP at both apical and basal dendritic synapses on hippocampal CA1 neurons. Brain Res 591:332-336. CrossRef Medline

Chih B, Engelman H, Scheiffele P (2005) Control of excitatory and inhibitory synapse formation by neuroligins. Science 307:1324-1328. CrossRef Medline

Chubykin AA, Atasoy D, Etherton MR, Brose N, Kavalali ET, Gibson JR, Südhof TC (2007) Activity-dependent validation of excitatory versus inhibitory synapses by neuroligin-1 versus neuroligin-2. Neuron 54:919931. CrossRef Medline

Comoletti D, De Jaco A, Jennings LL, Flynn RE, Gaietta G, Tsigelny I, Ellisman MH, Taylor P (2004) The Arg451Cys-neuroligin-3 mutation associated with autism reveals a defect in protein processing. J Neurosci 24: 4889-4893. CrossRef Medline

Dahlhaus R, El-Husseini A (2010) Altered neuroligin expression is involved in social deficits in a mouse model of the fragile X syndrome. Behav Brain Res 208:96-105. CrossRef Medline

Dahlhaus R, Hines RM, Eadie BD, Kannangara TS, Hines DJ, Brown CE, Christie BR, El-Husseini A (2010) Overexpression of the cell adhesion protein neuroligin-1 induces learning deficits and impairs synaptic plasticity by altering the ratio of excitation to inhibition in the hippocampus. Hippocampus 20:305-322. Medline

Daw NW, Stein PS, Fox K (1993) The role of NMDA receptors in information processing. Annu Rev Neurosci 16:207-222. CrossRef Medline

de Villers-Sidani E, Chang EF, Bao S, Merzenich MM (2007) Critical period window for spectral tuning defined in the primary auditory cortex (A1) in the rat. J Neurosci 27:180-189. CrossRef Medline

Dolleman-van der Weel MJ, Morris RG, Witter MP (2009) Neurotoxic lesions of the thalamic reuniens or mediodorsal nucleus in rats affect nonmnemonic aspects of watermaze learning. Brain Struct Funct 213:329_ 342. CrossRef Medline

Dresbach T, Neeb A, Meyer G, Gundelfinger ED, Brose N (2004) Synaptic 
targeting of neuroligin is independent of neurexin and SAP90/PSD95 binding. Mol Cell Neurosci 27:227-235. CrossRef Medline

Duncan GE, Moy SS, Perez A, Eddy DM, Zinzow WM, Lieberman JA, Snouwaert JN, Koller BH (2004) Deficits in sensorimotor gating and tests of social behavior in a genetic model of reduced NMDA receptor function. Behav Brain Res 153:507-519. CrossRef Medline

Fu Z, Washbourne P, Ortinski P, Vicini S (2003) Functional excitatory synapses in HEK293 cells expressing neuroligin and glutamate receptors. J Neurophysiol 90:3950-3957. CrossRef Medline

Gilman SR, Iossifov I, Levy D, Ronemus M, Wigler M, Vitkup D (2011) Rare de novo variants associated with autism implicate a large functional network of genes involved in formation and function of synapses. Neuron 70:898-907. CrossRef Medline

Glessner JT, Wang K, Cai G, Korvatska O, Kim CE, Wood S, Zhang H, Estes A, Brune CW, Bradfield JP, Imielinski M, Frackelton EC, Reichert J, Crawford EL, Munson J, Sleiman PM, Chiavacci R, Annaiah K, Thomas K, Hou C, et al. (2009) Autism genome-wide copy number variation reveals ubiquitin and neuronal genes. Nature 459:569-573. CrossRef Medline

Hines RM, Wu L, Hines DJ, Steenland H, Mansour S, Dahlhaus R, Singaraja RR, Cao X, Sammler E, Hormuzdi SG, Zhuo M, El-Husseini A (2008) Synaptic imbalance, stereotypies, and impaired social interactions in mice with altered neuroligin 2 expression. J Neurosci 28:6055-6067. CrossRef Medline

Hung AY, Futai K, Sala C, Valtschanoff JG, Ryu J, Woodworth MA, Kidd FL, Sung CC, Miyakawa T, Bear MF, Weinberg RJ, Sheng M (2008) Smaller dendritic spines, weaker synaptic transmission, but enhanced spatial learning in mice lacking Shank1. J Neurosci 28:1697-1708. CrossRef Medline

Hutsler JJ, Zhang H (2010) Increased dendritic spine densities on cortical projection neurons in autism spectrum disorders. Brain Res 1309:83-94. CrossRef Medline

Huttner WB, Schiebler W, Greengard P, De Camilli P (1983) Synapsin I (protein I), a nerve terminal-specific phosphoprotein. III. Its association with synaptic vesicles studied in a highly purified synaptic vesicle preparation. J Cell Biol 96:1374-1388. CrossRef Medline

Iida J, Hirabayashi S, Sato Y, Hata Y (2004) Synaptic scaffolding molecule is involved in the synaptic clustering of neuroligin. Mol Cell Neurosci 27: 497-508. CrossRef Medline

Insel TR, Fernald RD (2004) How the brain processes social information: searching for the social brain. Annu Rev Neurosci 27:697-722. CrossRef Medline

Izquierdo A, Jentsch JD (2012) Reversal learning as a measure of impulsive and compulsive behavior in addictions. Psychopharmacology 219:607620. CrossRef Medline

Jamain S, Quach H, Betancur C, Råstam M, Colineaux C, Gillberg IC, Soderstrom H, Giros B, Leboyer M, Gillberg C, Bourgeron T (2003) Mutations of the X-linked genes encoding neuroligins NLGN3 and NLGN4 are associated with autism. Nat Genet 34:27-29. CrossRef Medline

Jamain S, Radyushkin K, Hammerschmidt K, Granon S, Boretius S, Varoqueaux F, Ramanantsoa N, Gallego J, Ronnenberg A, Winter D, Frahm J, Fischer J, Bourgeron T, Ehrenreich H, Brose N (2008) Reduced social interaction and ultrasonic communication in a mouse model of monogenic heritable autism. Proc Natl Acad Sci U S A 105:1710-1715. CrossRef Medline

Janus C (2004) Search strategies used by APP transgenic mice during navigation in the Morris water maze. Learn Mem 11:337-346. CrossRef Medline

Jung SY, Kim J, Kwon OB, Jung JH, An K, Jeong AY, Lee CJ, Choi YB, Bailey $\mathrm{CH}$, Kandel ER, Kim JH (2010) Input-specific synaptic plasticity in the amygdala is regulated by neuroligin-1 via postsynaptic NMDA receptors. Proc Natl Acad Sci U S A 107:4710-4715. CrossRef Medline

Kim E, Sheng M (2004) PDZ domain proteins of synapses. Nat Rev Neurosci 5:771-781. CrossRef Medline

Kim J, Jung SY, Lee YK, Park S, Choi JS, Lee CJ, Kim HS, Choi YB, Scheiffele P, Bailey CH, Kandel ER, Kim JH (2008) Neuroligin-1 is required for normal expression of LTP and associative fear memory in the amygdala of adult animals. Proc Natl Acad Sci U S A 105:9087-9092. CrossRef Medline

Larson J, Lynch G (1988) Role of N-methyl-D-aspartate receptors in the induction of synaptic potentiation by burst stimulation patterned after the hippocampal theta-rhythm. Brain Res 441:111-118. CrossRef Medline

Larson J, Wong D, Lynch G (1986) Patterned stimulation at the theta frequency is optimal for the induction of hippocampal long-term potentiation. Brain Res 368:347-350. CrossRef Medline

Lord C, Cook EH, Leventhal BL, Amaral DG (2000) Autism spectrum disorders. Neuron 28:355-363. CrossRef Medline

Mayford M, Bach ME, Huang YY, Wang L, Hawkins RD, Kandel ER (1996) Control of memory formation through regulated expression of a CaMKII transgene. Science 274:1678-1683. CrossRef Medline

McKirdy J, Sussmann JE, Hall J, Lawrie SM, Johnstone EC, McIntosh AM (2009) Set shifting and reversal learning in patients with bipolar disorder or schizophrenia. Psychol Med 39:1289-1293. CrossRef Medline

Messeri P, Eleftheriou BE, Oliverio A (1975) Dominance behavior: a phylogenetic analysis in the mouse. Physiol Behav 14:53-58. CrossRef Medline

Meyer G, Varoqueaux F, Neeb A, Oschlies M, Brose N (2004) The complexity of PDZ domain-mediated interactions at glutamatergic synapses: a case study on neuroligin. Neuropharmacology 47:724-733. CrossRef Medline

Moore DR, Irvine DR (1979) The development of some peripheral and central auditory responses in the neonatal cat. Brain Res 163:49-59. CrossRef Medline

Moy SS, Nadler JJ, Perez A, Barbaro RP, Johns JM, Magnuson TR, Piven J, Crawley JN (2004) Sociability and preference for social novelty in five inbred strains: an approach to assess autistic-like behavior in mice. Genes Brain Behav 3:287-302. CrossRef Medline

Moy SS, Nadler JJ, Magnuson TR, Crawley JN (2006) Mouse models of autism spectrum disorders: the challenge for behavioral genetics. Am J Med Genet C Semin Med Genet 142C:40-51. CrossRef Medline

Otmakhova NA, Otmakhov N, Lisman JE (2002) Pathway-specific properties of AMPA and NMDA-mediated transmission in CA1 hippocampal pyramidal cells. J Neurosci 22:1199-1207. Medline

Pardo CA, Eberhart CG (2007) The neurobiology of autism. Brain Pathol 17:434-447. CrossRef Medline

Peça J, Feliciano C, Ting JT, Wang W, Wells MF, Venkatraman TN, Lascola CD, Fu Z, Feng G (2011) Shank3 mutant mice display autistic-like behaviours and striatal dysfunction. Nature 472:437-442. CrossRef Medline

Penzes P, Cahill ME, Jones KA, VanLeeuwen JE, Woolfrey KM (2011) Dendritic spine pathology in neuropsychiatric disorders. Nat Neurosci 14: 285-293. CrossRef Medline

Petralia RS, Sans N, Wang YX, Wenthold RJ (2005) Ontogeny of postsynaptic density proteins at glutamatergic synapses. Mol Cell Neurosci 29: 436-452. CrossRef Medline

Philippe A, Martinez M, Guilloud-Bataille M, Gillberg C, Råstam M, Sponheim E, Coleman M, Zappella M, Aschauer H, Van Maldergem L, Penet C, Feingold J, Brice A, Leboyer M, van Malldergerme L (1999) Genomewide scan for autism susceptibility genes. Paris Autism Research International Sibpair Study. Hum Mol Genet 8:805-812. CrossRef Medline

Poglia L, Muller D, Nikonenko I (2011) Ultrastructural modifications of spine and synapse morphology by SAP97. Hippocampus 21:990-998. Medline

Prange O, Wong TP, Gerrow K, Wang YT, El-Husseini A (2004) A balance between excitatory and inhibitory synapses is controlled by PSD-95 and neuroligin. Proc Natl Acad Sci U S A 101:13915-13920. CrossRef Medline

Robbins EM, Krupp AJ, Perez de Arce K, Ghosh AK, Fogel AI, Boucard A, Südhof TC, Stein V, Biederer T (2010) SynCAM 1 adhesion dynamically regulates synapse number and impacts plasticity and learning. Neuron 68:894-906. CrossRef Medline

Sans N, Prybylowski K, Petralia RS, Chang K, Wang YX, Racca C, Vicini S, Wenthold RJ (2003) NMDA receptor trafficking through an interaction between PDZ proteins and the exocyst complex. Nat Cell Biol 5:520-530. CrossRef Medline

Sara Y, Biederer T, Atasoy D, Chubykin A, Mozhayeva MG, Südhof TC, Kavalali ET (2005) Selective capability of SynCAM and neuroligin for functional synapse assembly. J Neurosci 25:260-270. CrossRef Medline

Schapitz IU, Behrend B, Pechmann Y, Lappe-Siefke C, Kneussel SJ, Wallace KE, Stempel AV, Buck F, Grant SG, Schweizer M, Schmitz D, Schwarz JR, Holzbaur EL, Kneussel M (2010) Neuroligin 1 is dynamically exchanged at postsynaptic sites. J Neurosci 30:12733-12744. CrossRef Medline

Schiller J, Schiller Y (2001) NMDA receptor-mediated dendritic spikes and 
coincident signal amplification. Curr Opin Neurobiol 11:343-348. CrossRef Medline

Shao Y, Wolpert CM, Raiford KL, Menold MM, Donnelly SL, Ravan SA, Bass MP, McClain C, von Wendt L, Vance JM, Abramson RH, Wright HH, Ashley-Koch A, Gilbert JR, DeLong RG, Cuccaro ML, Pericak-Vance MA (2002) Genomic screen and follow-up analysis for autistic disorder. Am J Med Genet 114:99-105. CrossRef Medline

Shipman SL, Nicoll RA (2012) A subtype-specific function for the extracellular domain of neuroligin 1 in hippocampal LTP. Neuron 76:309-316. CrossRef Medline

Shipman SL, Schnell E, Hirai T, Chen BS, Roche KW, Nicoll RA (2011) Functional dependence of neuroligin on a new non-PDZ intracellular domain. Nat Neurosci 14:718-726. CrossRef Medline

Tallafuss A, Constable JR, Washbourne P (2010) Organization of central synapses by adhesion molecules. Eur J Neurosci 32:198-206. CrossRef Medline

Tovar KR, Westbrook GL (1999) The incorporation of NMDA receptors with a distinct subunit composition at nascent hippocampal synapses in vitro. J Neurosci 19:4180-4188. Medline

van Zundert B, Yoshii A, Constantine-Paton M (2004) Receptor compartmentalization and trafficking at glutamate synapses: a developmental proposal. Trends Neurosci 27:428-437. CrossRef Medline

Vicini S, Wang JF, Li JH, Zhu WJ, Wang YH, Luo JH, Wolfe BB, Grayson DR (1998) Functional and pharmacological differences between recombinant N-methyl-D-aspartate receptors. J Neurophysiol 79:555-566. Medline
Vorhees CV, Williams MT (2006) Morris water maze: procedures for assessing spatial and related forms of learning and memory. Nat Protoc 1:848-858. CrossRef Medline

Washbourne P, Liu XB, Jones EG, McAllister AK (2004) Cycling of NMDA receptors during trafficking in neurons before synapse formation. J Neurosci 24:8253-8264. CrossRef Medline

Wittenmayer N, Körber C, Liu H, Kremer T, Varoqueaux F, Chapman ER, Brose N, Kuner T, Dresbach T (2009) Postsynaptic Neuroliginl regulates presynaptic maturation. Proc Natl Acad Sci U S A 106:13564-13569. CrossRef Medline

Ylisaukko-oja T, Rehnström K, Auranen M, Vanhala R, Alen R, Kempas E, Ellonen P, Turunen JA, Makkonen I, Riikonen R, Nieminen-von Wendt T, von Wendt L, Peltonen L, Järvel ä I (2005) Analysis of four neuroligin genes as candidates for autism. Eur J Hum Genet 13:1285-1292. CrossRef Medline

Zheng CY, Wang YX, Kachar B, Petralia RS (2011) Differential localization of SAP102 and PSD-95 is revealed in hippocampal spines using superresolution light microscopy. Commun Integr Biol 4:104-105. Medline

Zhiling Y, Fujita E, Tanabe Y, Yamagata T, Momoi T, Momoi MY (2008) Mutations in the gene encoding CADM1 are associated with autism spectrum disorder. Biochem Biophys Res Commun 377:926-929. CrossRef Medline

Zoghbi HY (2003) Postnatal neurodevelopmental disorders: meeting at the synapse? Science 302:826-830. CrossRef Medline 